\title{
Synthesis of global satellite observations of magmatic and volcanic deformation: implications for volcano monitoring $\&$ the lateral extent of magmatic domains
}

S. K. Ebmeier ${ }^{1 *}$, B. J. Andrews², M. C. Araya ${ }^{3}$, D. W. D. Arnold ${ }^{3}$, J. Biggs ${ }^{3}$, C. Cooper ${ }^{4}$, E. Cottrell ${ }^{2}$, M. Furtney ${ }^{5}$,

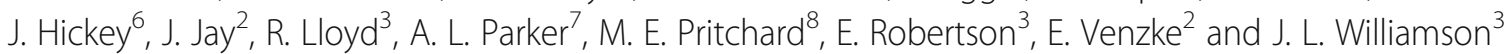

\begin{abstract}
Global Synthetic Aperture Radar (SAR) measurements made over the past decades provide insights into the lateral extent of magmatic domains, and capture volcanic process on scales useful for volcano monitoring. Satellite-based SAR imagery has great potential for monitoring topographic change, the distribution of eruptive products and surface displacements (InSAR) at subaerial volcanoes. However, there are challenges in applying it routinely, as would be required for the reliable operational assessment of hazard. The deformation detectable depends upon satellite repeat time and swath widths, relative to the spatial and temporal scales of volcanological processes. We describe the characteristics of InSAR-measured volcano deformation over the past two decades, highlighting both the technique's capabilities and its limitations as a monitoring tool. To achieve this, we draw on two global datasets of volcano deformation: the Smithsonian Institution Volcanoes of the World database and the Centre for the Observation and Modelling of Earthquakes, Volcanoes and Tectonics volcano deformation catalogue, as well as compiling some measurement characteristics and interpretations from the primary literature.

We find that a higher proportion of InSAR observations capture non-eruptive and non-magmatic processes than those from ground-based instrument networks, and that both transient ( $<$ month) and long-duration (> 5 years) deformation episodes are under-represented. However, satellite radar is already used to assess the development of extended periods of unrest and long-lasting eruptions, and improved spatial resolution and coverage have resulted in the detection of previously unrecognised deformation at both ends of the spatial scale $\left(\sim 10\right.$ to $\left.>1000 \mathrm{~km}^{2}\right)$. 'Baseline' records of past InSAR measurements, including 'null' results, are fundamental for any future interpretation of interferograms in terms of hazard, both by providing information about past deformation at an individual volcano, and for assessing the characteristics of deformation that are likely to be detectable (and undetectable) using InSAR.

More than half of all InSAR deformation signals attributed to magmatic processes have sources in the shallow crust ( $<5 \mathrm{~km}$ depth). While the depth distribution of InSAR-derived deformation sources is affected by measurement limitations, their lateral distribution provides information about the extent of active magmatic domains. Deformation is common ( $24 \%$ of all potentially magmatic events) at loci $\geq 5 \mathrm{~km}$ away from the nearest active volcanic vent. This demonstrates that laterally extensive active magmatic domains are not exceptional, but can comprise the shallowest part of trans-crustal magmatic systems in a range of volcanic settings.
\end{abstract}

Keywords: Monitoring, Volcano, InSAR, Satellite, Deformation, Database, Magma, Mush

\footnotetext{
* Correspondence: s.k.ebmeier@leeds.ac.uk

'School of Earth \& Environment, University of Leeds, Leeds LS2 9JT, UK

Full list of author information is available at the end of the article
} 


\section{Introduction}

Monitoring data have been described as the "only scientifically valid basis for short-term forecasts of a future eruption, or of possible changes during an ongoing eruption" (Tilling, 2008). Ideally, such data should be collected and analysed in real (or near-real) time and be done so consistently over long periods. In practise, continuous measurements from seismometers, tiltmeters and Global Positioning System (GPS) form the basis of most monitoring data streams, occasionally supplemented by field campaigns, gas and geochemical measurements (e.g., Sparks et al., 2012). Satellite-based Synthetic Aperture Radar (SAR) measurements have the potential to make a significant contribution to volcano monitoring (e.g., Pinel et al., 2014), especially in the form of regional surveys and for remote volcanoes with limited monitoring infrastructure.

The focus of most research in the application of SAR imagery in volcanology has been Interferometric SAR (InSAR), where the change in phase between timeseparated radar images is used to measure displacements of the Earth's surface on a centimetre to millimetre scale using interferograms (e.g., Bürgmann et al., 2000). Such measurements capture a wide range of magmatic, hydrothermal and structural processes (e.g., Prichard \& Simons, 2004; Biggs et al., 2009), including deformation during pre-eruptive unrest and during eruptions (e.g., Lu et al., 2010; Sigmundsson et al., 2010). Deformation measurements make a broad range of contributions to hazard assessment at volcanoes, from providing the sole evidence that a magmatic system is active (e.g., Pritchard \& Simons, 2004; Biggs et al., 2011), to distinguishing between tectonic and magmatic deformation mechanisms (e.g., Biggs et al., 2009, Ebmeier et al., 2016) to making eruption forecasts from analysis of variation in system overpressure (e.g., Hreinsdottir et al.).

InSAR measurements have now been made at over 500 volcanoes worldwide (including null results; Fournier et al., 2010; Biggs et al., 2014; supplemental material in Biggs and Pritchard, 2017; Global Volcanism Program, 2013) and have advanced our understanding of many of the physical processes that drive deformation (e.g., Pinel et al., 2014; Biggs \& Pritchard, 2017 and references therein). However, the use of interferograms for volcano monitoring, especially in a decision-making context, remains challenging due to delays between data acquisition and delivery of 'raw' imagery, the historical lack of freely available imagery, and to a dearth of the experience needed to interpret diverse satellite datasets in many observatories (e.g., Dzurisin, 2000).

This article describes global datasets of InSAR observations of volcano deformation and draws primarily on the Smithsonian Institution Global Volcanism Program (GVP) Volcanoes of the World database (from here on referred to as VOTW) and for the Centre for the Observation and Modelling of Earthquakes, Volcanoes and Tectonics (COMET) volcano deformation catalogue. Some additional deformation measurement characteristics were compiled for this article (data sources are described). From a snapshot of these databases, we describe the temporal and spatial characteristics of InSAR-measured deformation at volcanoes. This allows us to examine two issues concerning the measurement and recording of deformation: (1) the type of magmatic processes we are most likely to be able to detect with InSAR and how these compare to groundbased measurements; and (2) considerations for constructing catalogues or databases of volcano deformation to provide accurate baseline data for future monitoring. We also discuss the implications of InSAR observations for our understanding of the location and lateral extent of magmatic systems.

\section{SAR data \& volcano monitoring}

The pixels of SAR images contain an amplitude and a phase component, both of which provide information relevant to volcano monitoring (Fig. 1). Variations in SAR amplitude occur when the reflectivity or scattering properties of the surface of a volcano change (e.g., Pallister et al., 2013) and can be used to assess the shape of volcanic structures during eruption or unrest, including detecting the development of new eruptive vents, dome growth (e.g., Wang et al., 2015; Ozawa \& Kozono, 2013) and the emplacement of flow and eruptive deposits (e.g., Meyer et al., 2015). On the scale of days to weeks, SAR observations of dome and crater changes from amplitude imagery have provided critical information during volcanic crises at Soufrière Hills, Montserrat (Wadge et al., 1999) and Merapi, Indonesia (Pallister et al., 2013). Radar images are particularly important because they can be made through clouds and at night when visual observations are not possible.

InSAR methods require at least a pair, (and preferably a longer time series), of SAR images to analyse the variation in phase. Variations in radar phase are a consequence of relative ground motion and/or changes to the surface scattering properties (as well as nuisance factors including path delays through the atmosphere due to changes in refractivity). Measurements of displacements are made from interferograms, maps of shifts in radar phase between images acquired at different times. As phase is cyclical, phase differences take the form of repeating 'fringes' with values between 0 and $2 \pi$, resulting in an ambiguity of $2 \pi$ in phase measurements. The main challenges of analysing InSAR data include solving for this ambiguity and identifying or correcting the contributions that other factors, such as variations in satellite position 


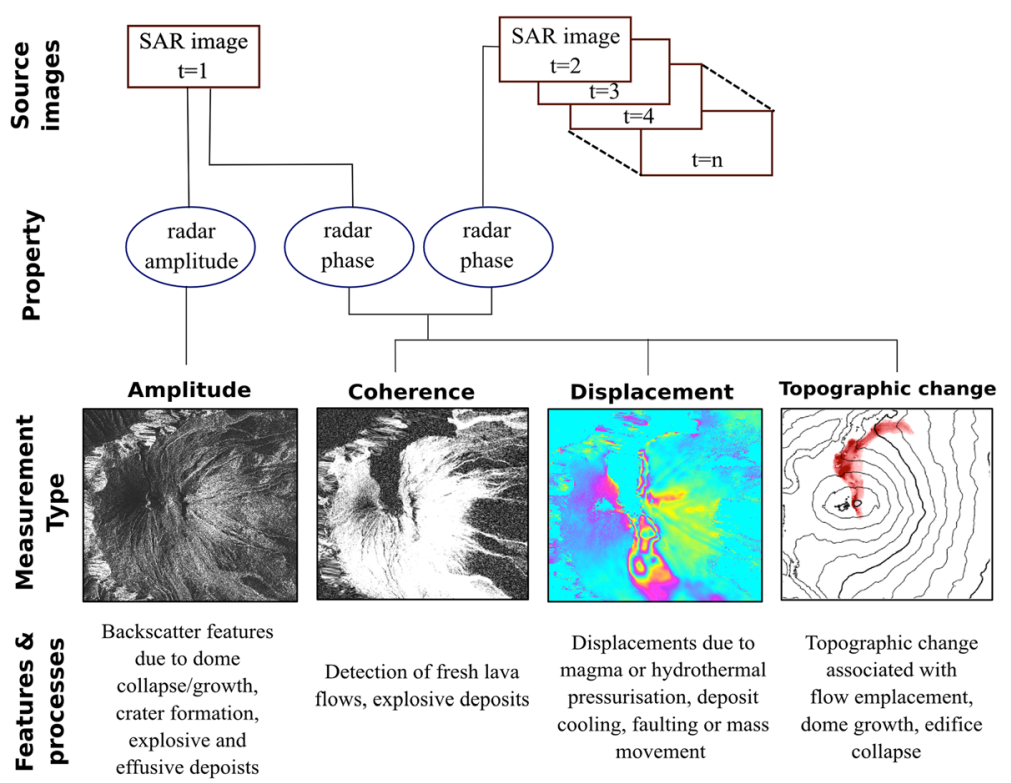

Fig. 1 Flowchart illustrating the current uses of SAR imagery and InSAR timeseries observations for volcano monitoring through the use of amplitude images, coherence changes in phase, ground displacements from differential InSAR and topographic change detection. Illustrative examples of amplitude, coherence and displacement data are from RADARSAT-2 images, while topographic change is derived from the analysis of TanDEM-X data at Reventador volcano, Ecuador (Arnold et al., 2017)

or atmospheric composition, make to phase (InSAR methods are reviewed by Simons \& Rosen, 2007). In addition, changes in the scattering properties of the Earth's surface may result in phase incoherence, making deformation measurement impossible. This is particularly problematic on steep volcanoes with frequent explosive eruptions or rockfalls, on volcanoes with ice caps and in regions of dense vegetation (e.g., Pinel et al., 2011; Ebmeier et al., 2013; Lu \& Dzurisin). Measurement thresholds have been lowered from centimetres to millimetres through the development of methods to correct atmospheric phase contributions (e.g., Parker et al., 2015; Bekaert et al., 2015), limit analysis only to stable ('persistent') scatterers (e.g., Hooper, 2008), and solve for deformation as part of a time series (approaches reviewed by Osmanoglu et al., 2016). Increasing numbers of systematic acquisitions by constellations of SAR satellite platforms offer the chance to improve on these detection thresholds, and provide the opportunity to apply signal processing approaches (e.g., independent component analysis, Ebmeier, 2016) to the analysis of large, multi-temporal InSAR datasets.

Other types of measurement (beyond ground displacements), have also been derived from the phase component of SAR imagery and successfully demonstrated for use in volcano monitoring, including topographic differences and variations in the coherence of the phase signal (Figure 1). Changes to topography on a metre-scale related to dome growth or the emplacement of flow deposits can be retrieved from the phase component of SAR images that have close temporal but large spatial separation (e.g., Ebmeier et al., 2012; Arnold et al., 2016, Naranjo et al., 2016). This is most successfully achieved with bistatic image pairs (close to simultaneously acquired, but spatially separated pairs of images) acquired by satellite missions designed for the measurement of topography (e.g. DLR's TanDEM-X, Albino et al., 2015). Although the effectiveness of SAR measurements of topography during an effusive eruption have been demonstrated (Poland, 2014), such bistatic data are not yet widely available for use in monitoring. Finally, interferometric phase coherence captures how rapidly surface scatterers are changing and can in some circumstances be used to track the development of fresh lava flows as they are emplaced, settle and cool (e.g. Dietterich et al., 2012). Incoherence, caused by the emplacement of fresh explosive deposits including pyroclastic flows and ash fall, also has potential for tracking eruption progress, especially in conjunction with SAR amplitude measurements.

The contribution that InSAR and SAR data make to volcano monitoring varies between economic settings. In some regions, especially where volcano observatories ${ }^{1}$ employ specialist staff, interferograms are integrated into the data streams relied upon for decision-making, notably the Alaska Volcano Observatory (Meyer et al., 2015), the Hawai'i Volcano Observatory (Poland et al., 2008), Italian 
volcanoes (Buongiorno et al., 2008), at La Réunion (Peltier et al., 2010) and in Iceland (Sigmundsson et al., 2015b). The utilisation of new technology (Poland, 2014), developments in analysis and near real-time data integration (Meyer et al., 2015) and use of geodetic measurements in remote settings ( $\mathrm{Lu}$ \& Dzurisin, 2014) have all been driven by monitoring goals. For some observatories where SAR data are not integrated into monitoring streams, especially in Middle Income Countries (as defined by the Organisation for Economic Co-operation and Development Development Assistance Committee, OECD-DAC), SAR measurements have nevertheless been used to supplement ground-based measurements, especially where instrumental networks are sparse (e.g., Delgado et al., 2017; Ebmeier et al., 2016). Where local observatories do not routinely processes and analyse SAR imagery, external organisations or research groups may do so (e.g., U.S.G.S. Volcano Disaster Assistance Program (VDAP) or Volcano Hazards Program, and Committee for Earth Observations Satellites (CEOS) Volcano Pilot). Projects such as the CEOS Volcano Pilot have demonstrated that SAR data provide unique information about volcanic unrest, which is complementary to established monitoring networks and valued by observatory scientists (Pritchard et al., n.d., under review). Where volcanoes are unmonitored, especially in Least Developed Countries, and where there have not been recent eruptions, InSAR measurements may provide the only source of information about volcanic unrest (e.g., Biggs et al., 2011). Such measurements often come from retrospective analyses of SAR data archives, and thus do not constitute true monitoring, although some pilot schemes are getting closer to that goal.

Displacement measurements from interferograms are included in analyses of multi-year trends in a volcano's activity by some volcano observatories (e.g., Wicks et al., 2006; Neri et al., 2009; Lu et al., 2010). In a few regions, over time windows of weeks to months, InSAR deformation measurements have contributed to datasets used to forecast the development of eruption (e.g., at Bardabunga, 2014, Sigmundsson et al., 2015a) or unrest (e.g., at Chiles-Cerro Negro, Ebmeier et al., 2016). At all volcanoes an understanding of deformation baseline is critical for interpreting new geodetic observations, and is especially important in absence of other geophysical datasets.

The number of SAR satellites providing data for research and geohazard applications has dramatically increased over the past two decades (e.g., Pritchard et al., n.d., under review; Elliott et al., 2016). Since the 1990s, the ranges of wavelengths available, swath coverages and repeat measurement intervals have increased (Table 1). Of particular note for volcanology are the shorter repeat times of a few days and higher ground resolutions (of a few metres) of the X-band satellites (TerraSAR-X) and constellations of satellites (COSMO-SkyMed), as well as the global coverage and free data supplied by Sentinel-1 and promised by the upcoming NASA-ISRO SAR (NISAR) mission.

\section{Identifying and interpreting magmatic and volcanic deformation}

Deformation identified as volcanic or magmatic is generally in a geographic region with evidence of past volcanic activity and is additionally either (1) localised on a volcanic edifice/deposits or (2) consistent with a pressure change within the Earth's crust. Most displacement signals that meet these criteria are related to structural (edifice growth and collapse), hydrothermal or magmatic processes. In most cases the spatial and temporal characteristics of magmatic deformation have limited overlap with those caused by tectonic or anthropogenic processes. However, ambiguities sometimes exist between magmatic and, for example, isostatic rebound (e.g., Lu \& Dzurisin, 2014) or hydrothermal deformation signals (e.g., Biggs et al., 2011). Distinguishing between hydrothermal and magmatic volume changes is particularly challenging, and not usually possible from geodetic data alone without additional constraints from gravity or conductivity measurements. Separating out the magmatic and tectonic elements of a deformation event may also be non-trivial, for example, during an episode of rifting (e.g., Biggs et al., 2009) or during moderate earthquakes that sometimes accompany volcanic unrest or eruption (e.g., Diez et al., 2005; Ebmeier et al., 2016).

Magmatic deformation can be broadly defined as relating to pressure changes within a magmatic system. A first order interpretation of deformation at a volcano is often one of a change in volume within a long-lived magma chamber or reservoir (which could be loosely defined as a site of repeated intrusion). However, InSAR displacements have also been attributed to other physical mechanisms, including, but not limited to, one-off emplacement of dykes or sills (often called simply 'intrusions'), phase changes (e.g., Caricchi et al., 2014), and the interaction of magma with a conduit system (e.g., Stephens et al., 2017). Parts of the crust where magma is stored are currently understood to include zones of partially crystalline mush, more mobile lenses of lower crystal fraction, and a higher crystal fraction framework. Zones of magma storage are expected to be spatially complex, with temporally varying types of connectivity between different parts of the system, allowing both the development of distinct chemical compositions and the 


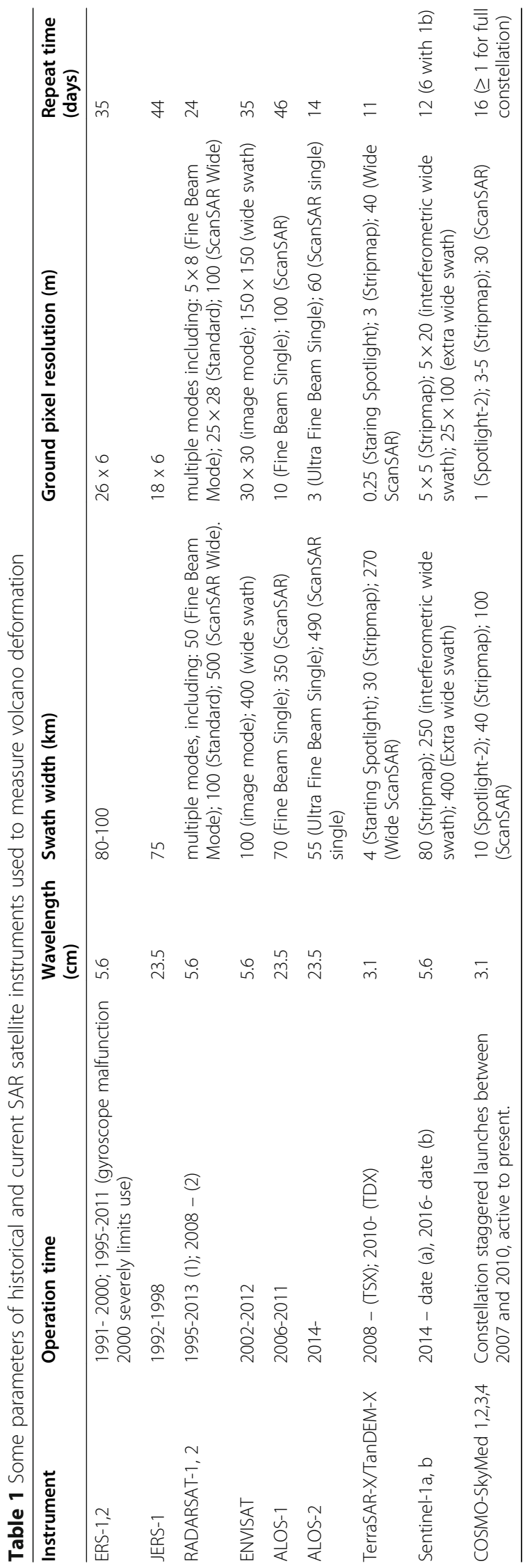


assembly of mobile (and therefore eruptible) magma. Such systems as a whole have been designated 'transcrustal magmatic systems' (e.g., Cashman et al., 2017), while magma storage zones of unknown structure and connectivity have been termed 'magmatic domains' (e.g., Sigmundsson, 2016).

The links between geodetic sources and the characteristics of complex magmatic domains are inherently ambiguous. A single observation of uplift, for example, does not allow us to discriminate between a one-off intrusion and the latest cycle of growth of a long-lived reservoir. Furthermore, we cannot necessarily discriminate between a pressure change throughout an entire system and one limited to some small section of a larger whole, i.e. we do not know what fraction of the magmatic system is involved in the deformation. However, if a deforming system can also be imaged tomographically (e.g., as a zone of low seismic velocity, Sigmundsson, 2016), then the relationship between the actively deforming sections and broader magmatic domain can be assessed.

This article synthesises volcanic and magmatic displacement measurements made around the world by a broad range of authors with diverse frameworks for the interpretation of measurements made over the past two decades. Here, we therefore describe 'deformation source' characteristics, rather than imposing terminology associated with different physical interpretations by different authors, e.g., 'chamber', 'reservoir' or 'intrusion'. We refer to the full extent of magma storage throughout the crust as a transcrustal magmatic system, but use the term 'magmatic domain' more generally to describe a part of that system - for example, a region examinable from a particular type of measurement. We discuss the implications of the global InSAR deformation dataset for understanding magmatic processes in the discussion.

\section{Insights from global InSAR volcano deformation measurements}

InSAR measurements have provided a diverse picture of magmatic processes in different tectonic settings. One major advance provided by InSAR data is the possibility of regional surveys, which have now been carried out at most of the Earth's major volcanic arcs (Alaska/Aleutians, Mexico/Central America, Northern-Central-SouthernAustral Andes, Indonesia \& Japan). The incorporation of 'null' results into such studies has allowed global statistical demonstration of the association between deformation and eruption (Biggs et al., 2014) and the observations that some smaller volume (< VEI 3) eruptions at stratovolcanoes take place without generating measurable deformation (e.g., Pritchard \& Simons, 2004, Moran et al., 2006, Ebmeier et al., 2013).
InSAR studies have revealed differences in magmatic systems related to tectonic settings. At volcanic arcs InSAR measurements have provided evidence for deformation sources at a range of depths (e.g., Lu \& Dzurisin, 2014), including the growth of mid-to lower crustal plutons (e.g., Pritchard \& Simons, 2004; Ruch et al., 2008) and shallow, extensive bodies aligned with the arc azimuth that subside during great earthquakes (Pritchard et al., 2013; Takada and Fukushima, 2013). Both long term (e.g., Parker et al., 2014) and transient subsidence (Caricchi et al., 2014) have been interpreted in terms of phase changes related to the cooling of an intrusion.

InSAR observations have provided major insights into the progression of rifting episodes and fissure eruptions in East Africa (e.g., Wright et al., 2006; Biggs et al., 2009; Pagli et al., 2012) and Iceland (Sigmundsson et al., 2015a, b). These have included the observations that magma is supplied to the crust intermittently, rather than steadily, and that its storage is distributed over multiple locations and depths in the lead up to a rifting episode (Wright et al., 2012; Biggs et al., 2016). Ascent into the shallow crust encompasses both repeated sill intrusion and multiple, interacting dykes (e.g., Hamling et al., 2010). Rift zones are extensively intruded by interconnected lenses of melt (e.g., Heise et al., 2007), but InSAR measurements have nevertheless shown the importance of repeated deformation originating beneath volcanoes and of repeated sill intrusion, which also seem to play a role in rifting events. For example, uplift attributed to sill intrusion at Alu and Gabho in Ethiopia preceded the Alu-Dalafilla and Dabbahu rifting episodes, respectively (Pagli et al., 2012), and similarly a deformation source beneath dormant Gelai volcano was active during rifting in Tanzania (Biggs et al., 2013). In contrast, neither long term uplift nor subsidence in the Taupo Volcanic Zone New Zealand, are associated with major volcanic features, but are centred beneath the Bay of Plenty and the boundaries between calderas in the Taupo volcanic zone, respectively (Hamling et al., 2016; Hamling et al., 2015).

The measurement of deformation at ocean islands with InSAR presents particular challenges due to the lack of far field observations, especially where only a fraction of the full displacement field may be discernible (e.g., Gonzalez, et al., 2013; Lu \& Dzurisin, 2014). Long-lived hotspot eruptions at Kilauea, Hawai'i (e.g., Poland et al., 2008) and Piton de la Fournaise, Réunion (e.g., Peltier et al., 2010), as well as repeated episodes of intrusion in the Galapagos (e.g., Bagnardi et al., 2013) dominate the small number of systems worldwide where multiple cycles of eruption have been observed geodetically (although this also includes non-hotpot volcanoes such as Okmok, Aleutians, Biggs et al., 2010a). As well as cycles of pre-eruptive uplift followed by co-eruptive subsidence, such long-lived 
eruptions have also provided evidence for endogenous growth, change in intrusion location in response to varying stress fields (e.g., Bagnardi et al., 2013) and cycles of feedback related to topographic structures (e.g., Jónsson, 2009; Lénat et al., 2012).

\section{Data sources: Catalogues and databases of volcano deformation}

Freely accessible catalogues and databases of past volcanic eruptions, activity and unrest are critical for identifying gaps in current observations and for understanding the context of recent activity (e.g., Venezky \& Newhall, 2007; Brown et al., 2014; Loughlin et al., 2015). The dataset compiled for the Smithsonian Institution GVP's VOTW relational database (Global Volcanism Program, 2013) is being developed to allow deformation to be compared to eruptive parameters and other information including petrological and emission data. It contains data about all of the volcanoes known to have erupted in the past 10,000 years and is housed at the Department of Mineral Sciences at the National Museum of Natural History, Smithsonian Institution, Washington, D.C., USA. The addition of deformation (and emissions) data to this database has required the adoption of new database structures to allow database entries to be made for deformation and emission periods as well as eruptions. Any number of deformation periods can be added to the database for a particular volcano, with entries made for a set number of parameters including: start and end dates, method of observation (InSAR, GPS, tilt, etc.), direction of displacement, displacement and/or displacement rate, location of centre of deformation, spatial extent of deformation, likely cause of deformation, and remarks. In addition to this basic information, the database also aims to record modelling information where available, as well as sample images and appropriate references. VOTW currently includes 422 records of deformation measured at 198 different volcanoes. Users will be able to search for deformation data on the Smithsonian Institution GVP website (volcano.si.edu) and submit published measurements through a Microsoft Excel upload tool for GVP staff to approve and commit.

The COMET volcano deformation catalogue is, at this stage, an inventory of past observations of volcano deformation, designed to accompany and provide context for the release of the most recent Sentinel-1 interferograms for volcanoes around the world. In the long term the COMET catalogue should provide feeder information for the VOTW database. The COMET catalogue is currently hosted by the University of Bristol, UK (volcanodeformation.blogs.ilrt.org) and is designed as a repository for information about past observations of deformation, primarily, but not exclusively, from InSAR measurements, and largely recorded in 'free text' format. The catalogue is designed to allow community contributions, with most information recorded in 'free text' boxes (sample guidelines for contributors to the COMET deformation database are shown in Appendix 1). Volcano names, numbers and locations use the VOTW database conventions to ease future compatibility. Contributors are asked to select multiple options from a list of categories to describe the types of deformation measurement and the range of inferred causes before describing deformation characteristics in as much detail as possible. Catalogue entries are organised by volcano, with multiple observations recorded in the same entry. The COMET database currently includes entries for 1011 volcanoes, of which 464 have reported geodetic measurements (including null results). Although the majority of the information in the catalogue comes from publications, our intention is to provide a forum for sharing information from the 'grey' literature, including, for example, observations from otherwise unpublished student theses, conference abstracts, observatory reports and personal communications, which are allowed as references. The COMET catalogue records 'null' results - that is, a measurement of no deformation with a quantified uncertainty (or measurement threshold) over a particular time period (e.g., Moran et al., 2006; Ebmeier et al., 2013). Such data are critical for robust probabilistic analyses of links between measured deformation and outcomes in term of volcanic activity, but are rarely published.

Here we present a synthesis of observations based on a 'snapshot' subset of information from the VOTW and COMET databases (from March $2017^{2}$ ). Our combined dataset encompasses InSAR measurements of 339 episodes of deformation at 160 different subaerial volcanoes and is spread globally across all arcs, rifts and oceanic islands (note that as this encompasses just InSAR measurements, this total is lower than number of records in either database, and lower than the 485 episodes of deformation in the appendix to Biggs and Pritchard, 2017, which combines both InSAR and ground-based measurements). This work is focussed on parameters of individual deformation episodes including deformation episode duration, maximum deformation rate, approximate signal area ('footprint') and inferred depth of the associated source. Not all of this information is available for every deformation episode, or even every volcano. The uncertainties on some of the properties are also highly variable between catalogue entries. For example, the values for maximum displacement rate may be reported directly in publications or estimated from publication figures, and may therefore depend on the figure resolution and quality as well as the processing and reporting choices made by the authors. Inferred depth is non-unique, dependent on choice of model and optimisation method, as well as a normally incomplete knowledge of crustal properties, and can trade-off with estimated volume change (e.g., 
Masterlark, 2007; Hickey and Gottsmann, 2014). The majority of inverse modelling of geodetic data relies on analytical solutions for particular geometries and assumptions that the Earth's crust behaves as a homogeneous uniform half-space (e.g., Segall, 2010). The reliability of geodetically determined depths may therefore depend on assumptions about crustal rheology and whether any independent constraints on source depth and location inform the modelling. We discuss some of the challenges of classifying deformation data for a catalogue or database, along with strategies for making such exercises useful in the discussion section, below.

\section{Assessing the characteristics of volcano deformation}

In this article we discuss both direct observations of InSAR-measured signals, such as signal area and duration of displacements, as well as parameters derived from the InSAR measurements, such as deformation source location, displacement rate and source depth. We also use contextual information such as dates of eruptions and published interpretations of deformation signals in our discussions. This section describes considerations for defining parameters than best characterise both InSAR measurements and the episodes of deformation that they capture.

\section{Direct parameters of InSAR signals}

An estimation of signal duration is made by almost all publications that describe InSAR data and is included as an explicit record category (measured in days) in both the VOTW database and COMET deformation catalogue. The apparent duration of a deformation signal measured with InSAR depends both on its true duration and on the satellite repeat time. It is sometimes possible to assess the duration of deformation episodes that are shorter than satellite repeat time if multiple satellites have acquired data or if a correlation with independent measurements of unrest, such as seismicity, is assumed (e.g., Sigmundsson et al., 2015b). However, for at least one fifth of the InSAR observations in the VOTW database, deformation is thought to have started before or finished after the window of observation, and therefore only captures a fraction of the true signal duration (e.g., Chaussard et al., 2013). The distribution of apparent durations in the VOTW and COMET databases are shown in Fig. 2A.

Displacement signal area is a critical consideration for designing monitoring networks, measurement campaigns and tasking satellite acquisitions. Signal area is reported in some entries of the COMET deformation catalogue, and we have supplemented this information from the primary literature (e.g., Additional file 1: Table S1). Whilst signal area can be inferred directly from InSAR data, it depends on both the properties of the deformation source (depth, volume or pressure change and geometry) and on the detection threshold for deformation in the InSAR data (which depends in turn on radar wavelength, time span of observations, look direction of satellite, number of
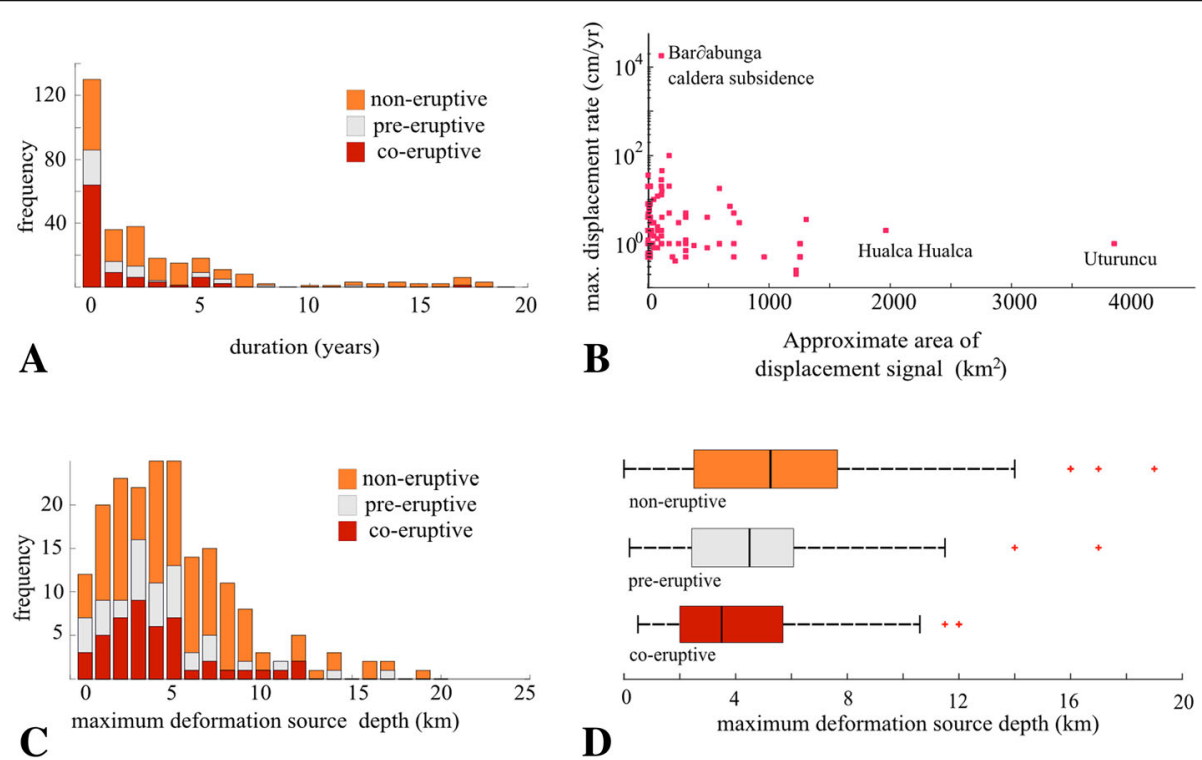

Fig. 2 a Frequency of the observed duration of InSAR-measured displacement episodes, subdivided by whether deformation occurred in the period leading up to eruption (grey), during eruption (red) or during an inter-eruptive period (orange). b Relationship between approximate area of displacement signal as detected from InSAR measurements and the maximum detected rate of displacement in $\mathrm{cm} / \mathrm{yr}$. Note that the $\mathrm{y}$-axis is logarithmic $\mathbf{c}$ Frequency of inferred maximum depths of deformation sources estimated from InSAR-measured displacements at intervals of $1 \mathrm{~km}$, with same colour scheme as part (A). d) Boxplots illustrating distribution of deformation source depths inferred from InSAR measurements of deformation. The central dark line indicates median value, the box limits show upper and lower quartiles and red crosses show the locations of outliers 
acquisitions in a time series, ability to reduce atmospheric noise, and level of coherence). Ideally it would be defined using a threshold displacement magnitude, relative to a far field location, but it is rarely possible to extract such information from publications. We therefore approximate deformation footprint areas by using the signal diameters provided by authors (or estimated from publication figures), assuming either a circular or elliptical shape. As signal areas have a range that spans orders of magnitude, this crude approximation is sufficient for a first order comparison with other properties (e.g., maximum displacement rate in Fig. 2B).

\section{Derived deformation source parameters}

The VOTW database records both mean and maximum displacement rate (in $\mathrm{cm} / \mathrm{yr}$ ), where it has been reported in the source publications. Mean displacement rates derived from total displacement in a single interferogram (or from the sum of a chain of images) can be calculated for most episodes in the dataset. However, mean displacement rates are only physically meaningful if the duration of deformation is equal to or greater than the time spanned by the interferogram(s). Maximum displacement rates estimated by the authors of InSAR studies and recorded in both VOTW and COMET databases are more likely to represent true deformation rates, but are limited by satellite repeat time. For example, the maximum displacement rate of a transient, but rapid, acceleration is likely to be underestimated if its duration was a small fraction of satellite repeat time. The highest deformation rates in our datasets (metres per day) were detected during caldera collapse at Bardabunga (Gudmundsson et al., 2016), and dyke opening during eruptions or rifting events (e.g., Pagli et al., 2012) where duration could be defined from independent data sources. Despite measurement limitations, some general trends can be observed in the relationship between displacement rate and other deformation signal parameters. There is a broad anti-correlation between displacement rate and duration (e.g., Fournier et al., 2010; Biggs \& Pritchard, 2017), as deformation rates above a few 10s $\mathrm{cm} / \mathrm{yr}$ tend not to continue longer than a few weeks to months (Laguna del Maule, $28 \mathrm{~cm} / \mathrm{yr}$., is a notable exception, e.g., Feigl et al., 2014). Deformation signals with large spatial footprints $\left(>1000 \mathrm{~km}^{2}\right)$ have low rates (Figure 2B) and have been attributed to the growth of plutonic bodies in the mid to lower crust (e.g., Pritchard \& Simons, 2004).

One of the most useful derived parameters is the depth of the inferred deformation source. Apparent depth of deformation depends both on the processes detected (e.g., the intrusion of a sill, overpressure of (part of) a reservoir or ascent of a diapir) and on the approach taken to modelling the geodetic data. Source depth depends on a range of factors relating to buoyancy, magma composition, stress conditions and pre-existing structural features (e.g., Chaussard \& Amelung, 2014), as well as conditions that promote the amalgamation of lenses of melt and volatiles in a mush system to form larger bodies of eruptible magma (e.g., Cashman et al., 2017). We do not discuss estimations of volume change here, because it is strongly dependent on the reservoir or intrusion compressibility, which is very poorly constrained, and depends on both magma and exsolved gas compressibilities as well as source geometry and material properties of the surrounding rock (e.g., Rivalta and Segall, 2008; Amoruso and Crescentini, 2009; McCormick Kilbride et al., 2016). Modelled source depth is recorded for some deformation episodes by both VOTW and COMET, and we build on this by including further preferred deformation source depths from publications (including any estimation of uncertainty provided). Such depths are affected by the assumptions required for modelling, as well as the spatial and temporal resolution of geodetic data (and therefore the SAR instrument used for measurement) and processing methods (e.g., single interferogram, time series, persistent scatterer). We do not attempt to separate out data from magmatic and hydrothermal sources here, but note the authors' interpretation of the deformation. Some of the shallower depths reported are therefore likely to relate to hydrothermal systems, so that any magma storage is actually deeper (e.g., at Campi Flegrei, Trasatti et al., 2008; Gottsmann et al., 2006). Figure $2 \mathrm{C}$ and D illustrate the distribution of inferred depths of deformation sources. For this figure we have used the maximum estimated source depth where a range of possible values have been evaluated, or where multiple depths have been suggested for the same deformation events. Only depths associated with potential sites of magma storage are included here (in practice, the majority of these are modelled as point, spherical, ellipsoidal, penny-shaped or sill-like sources - the depth ranges estimated for opening dykes are excluded).

\section{Summary of InSAR signal characteristics}

If we were to describe a 'modal' InSAR deformation signal from the global datasets described above, it would be attributed to the movement of magmatic or hydrothermal fluids within the shallow crust $(<5 \mathrm{~km}$ depth), not associated with an eruption, with a rate of a few $\mathrm{cm} / \mathrm{yr}$. and footprint area $<100 \mathrm{~km}^{2}$. The properties of this modal signal are primarily the consequence of the historical spatial and temporal boundaries of InSAR measurement, rather than evidence for a universally common deformation sources. In fact, we expect melt to be distributed at different fractions throughout the crust, with significant differences between rift zones, where melt fraction is expected to be high over large areas, and in arcs, where accumulation of higher melt fraction 
lenses will form melt-rich reservoirs at depths where stress conditions are favourable. However, characterisation of the depths and setting where most geodetic signals originate is a good starting point for assessing the processes for which SAR data are likely to be most useful for monitoring.

There is a peak in the number of displacement episodes in our study that suggest a maximum deformation source depth of 4-5 km (Fig. 2C), and only half of the deformation signals were thought to be deeper than this. That half of potentially magmatic source detected with InSAR are thought to lie in the shallow crust $(<5 \mathrm{~km})$ is unsurprising, given that pressure changes in shallow systems cause higher magnitude surface displacements, and are therefore more likely to be detected by InSAR measurement (i.e. small volumes changes in the mid to lower crust are unlikely to be detectable). It is likely that very shallow sources are underreported due to both the lower spatial sampling of many historical measurements and particularly where high deformation rates or eruptive products cause phase incoherence near active vents. Although the ranges of co-eruptive, pre-eruptive (here defined as occurring in the year before an eruption) and inter-eruptive inferred maximum depths largely overlap (Figure 2D), the mean value for deformation sources involved in co-eruptive deformation is $\sim 2 \mathrm{~km}$ shallower than that for those not associated with eruption. Whilst there are examples of volcanoes where co-eruptive subsidence is shallower than the pre-eruptive uplift (e.g., Eyjafjalljökull 2010, Sigmundsson et al., 2010), this is not always the case, and the difference in mean values is more likely to be because most examples of mid-lower crustal deformation are non-eruptive. Deformation sources with maximum depths deeper than $\sim 12 \mathrm{~km}$ were inferred only from displacements that occurred during inter-eruptive periods.

About $60 \%$ of InSAR measurements of deformation catalogued here (Fig. 2A) have estimated durations that exceed a year, and only $14 \%$ have durations shorter than a month (39 of 285 entries for which we have signal durations). Those thought to have lasted less than a month were almost all high magnitude (i.e. much larger that half radar wavelength) and produced displacements that endured at least as long as the satellite repeat time. Ground-based deformation measurements record a slightly higher proportion of deformation lasting less than a month $(20 \%)$. Pre-eruptive unrest lasting days to months, especially where deformation is low magnitude or transient, is likely to be under-represented in historical InSAR data. However, newer satellite missions with shorter repeat intervals (TerraSAR-X repeat $=11$ days, COSMOSkyMed constellation minimum repeat $=1$ 16 days) have recently made the measurement of rapid processes, particularly those connected to lava dome growth (e.g., Salzer et al., 2014) or conduit processes (e.g., Stephens et al., 2017), possible for the first time. At the other end of the scale, the duration of satellite missions (typically 5-10 years) is also potentially a limiting factor for detecting low-rate, long duration deformation. Ground-based measurements have captured 10\% more deformation signals lasting $>5$ years than InSAR, suggesting that the longest duration processes also remain under-represented. The planned long duration of current missions, especially the European Space Agency's 20 year commitment to the Sentinel-1 programme, should improve this in the coming decades. A small proportion of volcanoes have levelling survey data that extends back decades, providing evidence of many decades of subsidence (e.g., > 50 years at Medicine Lake, Parker et al., 2014; Santorini, Parks et al., 2012), uplift (decades e.g., Long Valley, Newman et al., 2006) or complex deformation sequences (e.g., 100s years, Campi Flegrei, Lundgren et al., 2001 and references therein). InSAR measurement has been possible since 1992 at the earliest, so the longest possible duration of InSAR deformation observations is 25 years, although in effect, measurements have been possible for a much shorter time in some parts of the world due to dense vegetation and low frequencies or gaps in image acquisitions.

The surface area of InSAR-measured volcano deformation ranges from $<1 \mathrm{~km}^{2}$ to $>3000 \mathrm{~km}^{2}$, with a mean value of $\sim 240 \mathrm{~km}^{2}$ (e.g., Figure $2 \mathrm{~B}$ ). The majority of ground displacement footprints are elliptical, and related to the elastic deformation of the crust caused by the movement of fluid, but shallow processes that involve a brittle component can produce more complex, irregular patterns (e.g., fracturing of pyroclastic flow deposits at Lascar, Andes, Whelley et al., 2012; and landsliding at Arenal, Costa Rica, Ebmeier et al., 2014). One of the most striking outcomes of regional InSAR surveys of volcano deformation (e.g., Pritchard \& Simons, 2004; Lu \& Dzurisin, 2014) has been the discovery of deformation taking place many kilometres away from the nearest recorded Holocene volcano. In Table 2, we list 33 observations of deformation where the centre of deformation is $\geq 5 \mathrm{~km}$ away from the volcano's summit, or in some cases the most recent vent. Offsets of $\geq 5 \mathrm{~km}$ are unlikely to be an artefact of the inclined SAR viewing geometry for deformation sources in the shallow crust. The 33 examples in Table 2 are limited to signals attributed to magmatic or hydrothermal processes (excluding a few examples of dykes opening which may, or may not be associated with long term storage of magma in the crust). Figure 6 also excludes instances where we are confident that the deformation measured was associated with a one-off intrusion rather than the development of a reservoir (e.g., one of Fernandina's multiple sill intrusions was $\sim 5 \mathrm{~km}$ away from its summit), although in 


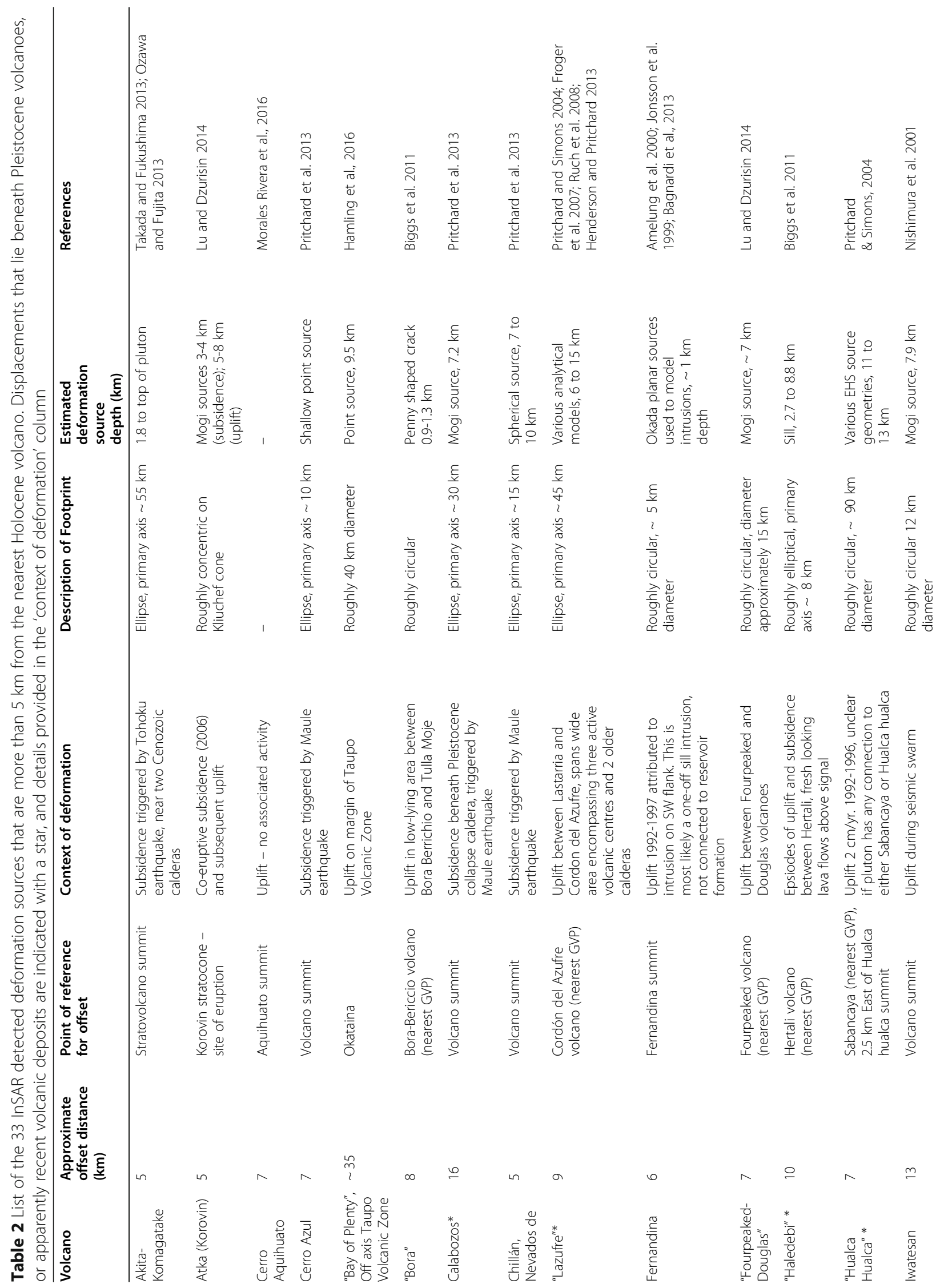




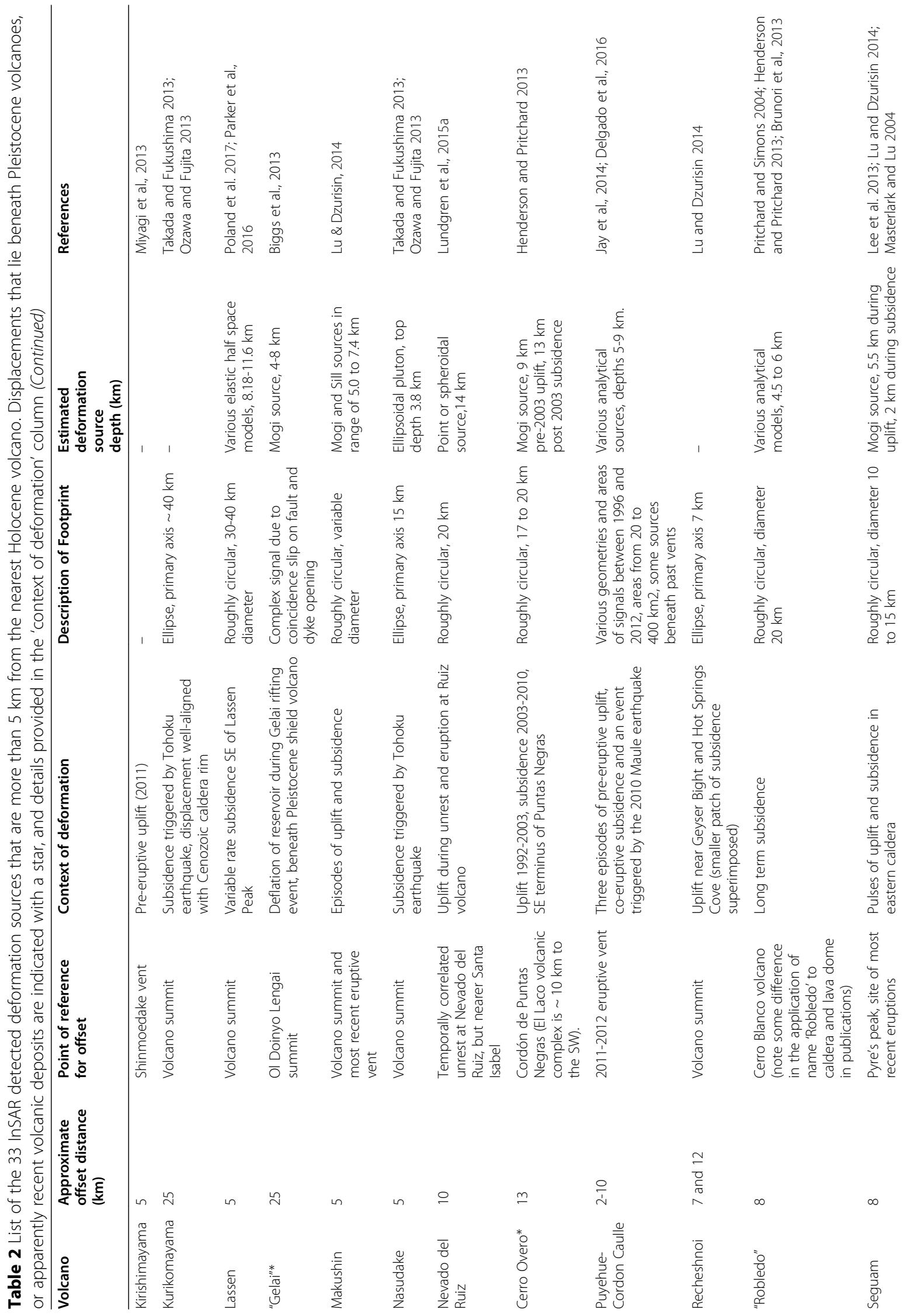




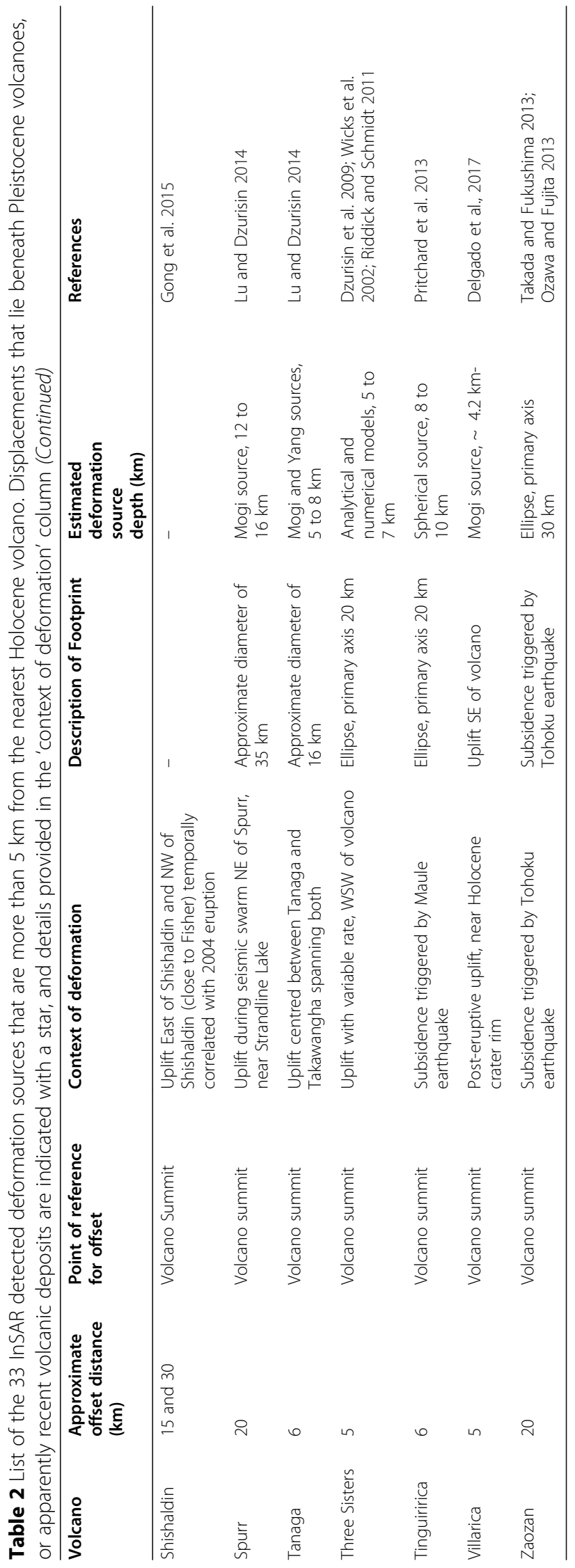


many cases we do not have the means to distinguish this. In several cases, such deformation lies beneath a volcanic edifice where deposit age is unknown (e.g., at Haledebi, Ethiopia; examples marked with a star in Table 2) and the volcano has not historically been in included in Holocene databases, although VOTW has recently been updated to include all Pleistocene volcanoes.

\section{Comparison between InSAR and ground-based measurements}

Some of the characteristics of volcanic and magmatic deformation signals measurable with InSAR can be illuminated by comparison to the properties of deformation measured with ground-based instrumentation. However, both the GVP VOTW database and the COMET catalogue also include deformation observations made from ground-based instrumentation. Figure 3 compares 339 observations of deformation made with InSAR (at 160 volcanoes) to 152 made with various ground-based instruments (at 77 volcanoes). It should be noted that there are many decades of ground-based measurements that have not yet been compiled into any database, and that form our only record of pre-satellite era deformation (e.g., deformation during unrest at 27 volcanoes described by Phillipson et al. (2013) and extracted from Global Volcanism Program weekly reports). There are some volcanoes in our datasets where both InSAR and ground-based measurements of deformation have been made, but many volcanoes appear in only one of the two datasets. Almost three times as many InSAR measurements capture non-eruptive processes relative to ground-based measurements (including GPS, tilt \& electronic distance meter) (Fig. 3). This is unsurprising, given that ground-based networks tend to be installed at volcanoes in response to recent activity, while InSAR studies can be conducted systematically in survey mode over large regions. Possibly because ground-based instruments are sited to avoid such effects, InSAR measurements have also detected a greater proportion of non-magmatic processes, including deformation associated with hydrothermal systems (e.g., Recheshnoi, Lu \& Dzurisin, 2014), the settling of recent flow deposits (e.g., Arenal, Ebmeier et al., 2010), fault slip (e.g., Gelai, Biggs et al., 2009) and gravitational failure (e.g,. Etna, Lundgren et al., 2004).

Of the 152 observations of deformation made with ground-based instruments from our snapshot of the VOTW database, 98 are from Developed Countries (DCs) and a further 19 from Upper Middle Income Countries (UMICS) and territories (2017 OECD-DAC list of Official Development Assistance recipients, www.oecd.org/dac/stats/daclist.htm), and $<2 \%$ of measurements come from Least Developed Countries (LDCs), although these countries have roughly $8 \%$ of Holocene volcanoes. LDCs are better represented in the global InSAR catalogue with $15 \%$ of all records (DCs and UMICS make up 70\% of observations). This illustrates the potential that satellite remote sensing has for monitoring volcanoes in LDCs, where funding for ground-based infrastructure is particularly limited.

\section{Temporal properties of volcanic and magmatic InSAR signals}

To be useful for hazard mitigation, monitoring data need to be available for analysis on the timescales over which hazards manifest (e.g., Loughlin et al., 2015). Decision makers with different responsibilities require hazard information at various timescales (black bars on Fig. 4A) and levels of detail, with an emphasis on uncertainty. For example, the United States Geological Survey operate dual volcano alert level systems to accommodate both the aviation industry, who require hazard information as rapidly as possible, and those responsible for hazard response on the ground who may prefer a lead time to inform and educate decision makers (Fearnley et al., 2012). While relevant information for long-term infrastructure and public service planning should capture broad changes between years or decades, monitoring data that feeds into decisions about evacuation must be available on much shorter timescales in as near to realtime as possible (Tilling, 2008).

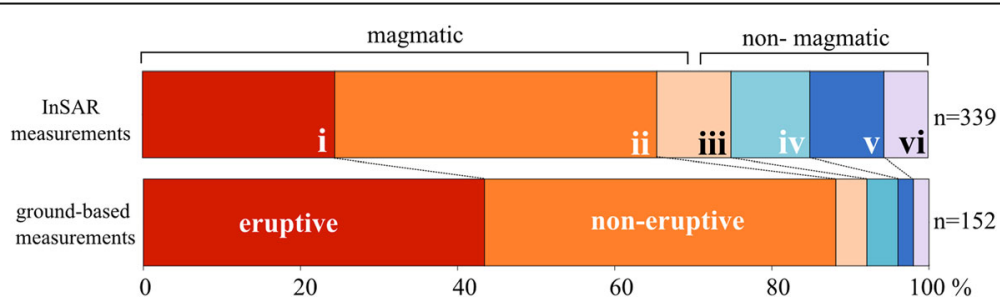

Fig. 3 Comparison of InSAR and ground based measurement in terms of inferred origins: i) attributed to magmatic processes during period of eruption, ii) attributed to magmatic processes not associated with eruption, iii) either magmatic or hydrothermal or both in combination, not associated with eruption, iv) attributed to hydrothermal system, v) settling of recent flow deposits and f) displacements associated with faulting or gravity driven collapse on any scale 


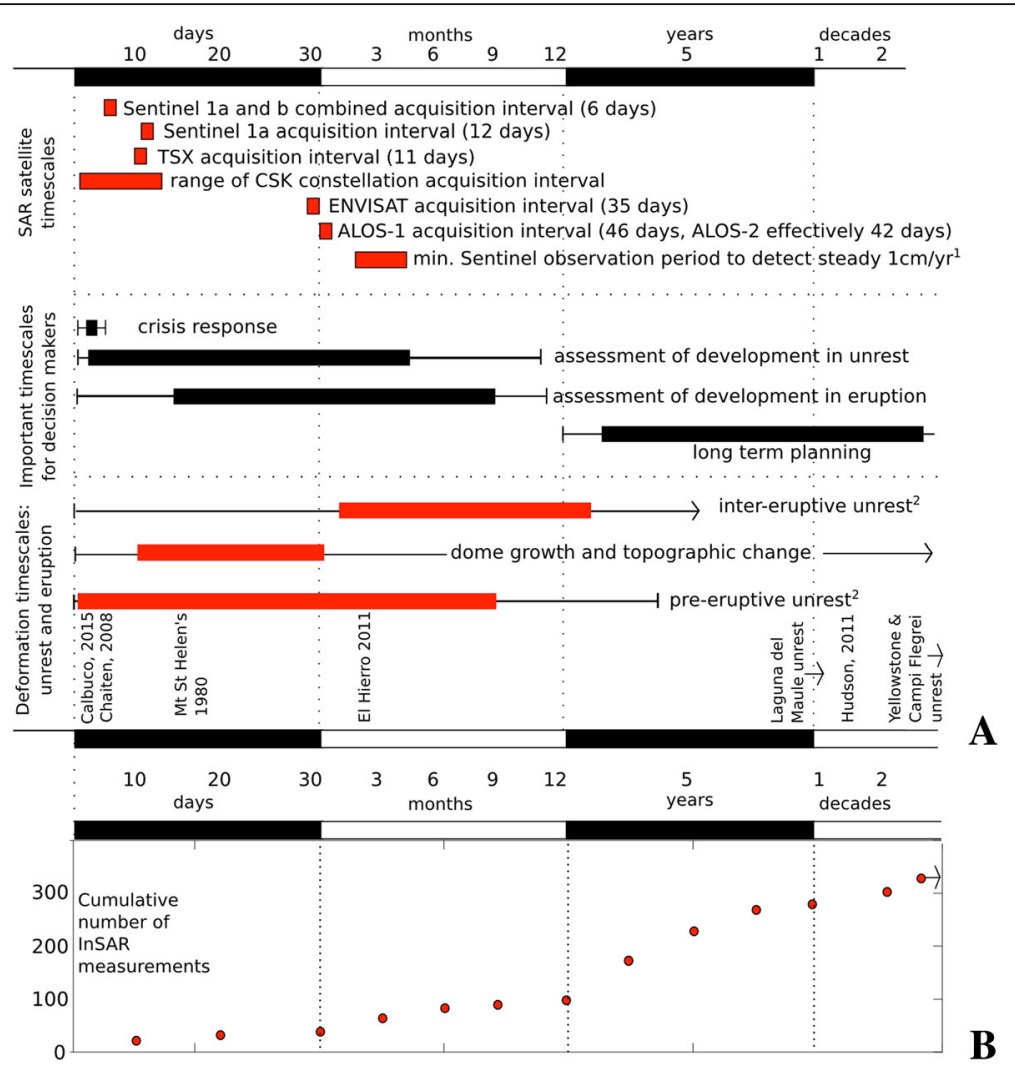

Fig. 4 a. Illustration of significant timescales for InSAR measurement (satellite repeat time, 'observation period as estimated by Parker et al., 2015), decision makers with responsibility for volcanic hazard (indicative durations) and duration of unrest and eruption ( ${ }^{2}$ unrest periods as described by Phillipson et al., 2013). Examples of eruptions with different durations of pre-eruptive unrest are indicated by volcano name and eruption date (López et al., 2012; Delgado et al., 2014), while volcano name and arrows show episodes of unrest. b. Cumulative number of InSAR measurements of volcano deformation that have captured various durations - note non-linear time scale on $\mathrm{x}$-axis

The processes that eventually lead to eruption, including the intrusion, migration and ascent of magmatic fluids, take place on a range of timescales from days to decades (indicative red bars on Fig. 4A). For monitoring, the most important of these is arguably the duration of any pre-eruptive unrest. Passarelli \& Brodsky, 2012 find that the duration of pre-eruptive unrest is generally longer for volcanoes with higher silica contents: from minutes to a year for basalts, and from days to years for andesites. Phillipson et al., (2013) find that the median duration of pre-eruptive unrest captured by monitoring networks varied significantly between different types of volcanoes, with pre-eruptive unrest at complex volcanoes lasting an average of just two days before eruption, about a month at stratovolcanoes and $>2$ months at shield volcanoes and calderas. The timescales over which an eruption evolves in character are also important for assessing volcanic hazard. Decrease in reservoir overpressure, for example, has been estimated from GPS (e.g. Hreinsdottir et al., 2014a; Mastin et al., 2008) and InSAR measurements (e.g., Sigmundsson et al., 2015a, b) over weeks to months. Deformation of a lava dome (hours to days, e.g. Salzer et al., 2014), change in effusion rate (days to months, e.g., Poland, 2014) or slip during mass wasting (over years, e.g., Froger et al., 2001; Solaro et al., 2010 or minutes e.g., Voight et al., 1981) may also indicate changes in hazard level during an ongoing eruption. Changes in such deformation signals may occur rapidly, or gradually over years, requiring measurement at regular intervals for detection. Satellite repeat intervals that exceed the duration of target deformation signals limit the timescales over which InSAR is appropriate for monitoring. Historically, satellite repeat times were 35-46 days (ERS, ENVISAT-ASAR, ALOS-PALSAR, Table 1) with actual measurement frequency being even lower in areas with seasonal snow cover or flooding and for instruments with limited power and acquisition strategy that did not prioritise volcanic hazard. The higher number of InSAR measurements for signal durations of $>12$ months (Fig. 4B) reflects the under-representation of signals lasting days to months in our records. The lack of a significant increase in the 
cumulative number of InSAR observations between one and two decades is a consequence of the limited time over which InSAR measurement has been possible. Presently, multiple cycles of eruption and intrusion have only been observed at a handful of volcanoes (e.g., Sigmundsson et al., 2010; Lu et al., 2010; Biggs et al., 2010a, b; Bagnardi et al., 2013), although cycles of activity within long-lasting eruption have been observed at several more (e.g., Poland et al., 2008; Peltier et al., 2010).

\section{Pre-eruptive deformation}

Pre-eruptive deformation can take a range of forms, but its utility for volcano monitoring and ultimately forecasting eruptions depends on our ability to interpret the process responsible and forecast its evolution. A simple definition would be any deformation that occurs in a specified time period leading up to an eruption, but at active, frequently erupting systems, it may be unclear whether this is related to the previous eruption or simply baseline activity.

About half of the deformation episodes in our catalogue occur in the year before a volcanic eruption or span the eruption itself (excluding flow deposit and gravity-driven subsidence). However, a more useful definition of 'pre-eruptive' might require the demonstration of a causal link to the eruption. This is relatively straight-forward where pre-eruptive uplift continues until the onset of eruption, and is followed by similar co-eruptive subsidence (e.g., at Okmok, 2008; Lu et al., 2010) or when the onset of deformation is correlated with seismicity (e.g., at El Hierro, Gonzalez et al., 2013). However, gaps of days to months between a period of observed inflation and the eventual eruption (e.g., at Kerinci, Sinabung and Slamet, Indonesia, Chaussard et al., 2013) make a connection with eruption harder to infer and interpret. Uplift preceding eruption can be of long duration (e.g., 6 years before the 2011 eruption of Hudson, Delgado et al., 2014), or continue after an eruption has taken place (c.f. 2012 phreatic eruption at Copahue, Velez et al., 2016). There are a growing number of observations of episodes of uplift occurring both months and years before the onset of eruption: the 2010 eruption of Eyjafjallajökull tapped sills both emplaced gradually in the three months before eruption, and a decade earlier (Sigmundsson et al., 2010). Such intrusions could only be classified as 'pre-eruptive' in retrospect. Distinguishing between a shallow preexisting reservoir being 'charged' by an intrusion (e.g., as interpreted at Santorini, Parks et al., 2012) and endogenous growth of a volcanic edifice (e.g., Tungurahua, Biggs et al., 2010a, b; Fernandina, Bagnardi et al., 2013) therefore requires an understanding of the pre-existing magmatic plumbing. These historical deformation measurements provide a useful baseline for interpreting future episodes of uplift in particular. For future monitoring, InSAR is likely to be useful for 'pulsed' reservoir charging, where the time between intrusion and eruption greatly exceeds satellite repeat time (but is also less than the total monitoring duration) and measurement of repeated intrusion allows a picture of the volume and location of eruptible magma to be built up.

\section{Spatial properties of volcanic and magmatic InSAR signals}

The high spatial density of InSAR displacement measurements over wide areas has revealed the areal extent of deformation fields that would previously only have been sampled at a handful of points. This includes highly localised deformation signals that occur between the gaps in ground based monitoring networks (e.g., Fig. 5A). In some cases localised deformation signals lie in network gaps by design - for example, where instruments are sited to avoid local subsidence associated with young flow deposits. In other cases (e.g., at Tungurahua, Fig. 5A; Galeras, Parks et al., 2011), InSAR has allowed the detection of displacement associated with magmatic intrusion beneath regions where the installation and maintenance of ground based instruments would have been too dangerous. All of the deformation signals attributed to magmatic processes detected thus far are smaller than the footprint of TOPS mode Sentinel-1 imagery $(\sim 250 \mathrm{~km})$, although several exceed the area of higher resolution instruments, such as COSMOSkyMed and TerraSAR-X (e.g., at Uturuncu, Lazufre, Lassen, Fig. 5B, Pritchard \& Simons, 2004; Ruch et al., 2008; Parker et al., 2016). For most displacement footprints 'offset' by $<5 \mathrm{~km}$, the volcano itself lies within the deformation footprint, but at greater offsets, a higher proportion of displacement footprints would not be detectable in measurements on the volcano's edifice itself, where ground-based instruments would usually be located (Fig. 5C).

Calderas typically have spatially and temporally variable deformation signals, as well as some of the highest rates of non-eruptive deformation detected using InSAR (Wicks et al., 2006; Le Mével et al., 2015; Jay et al., 2014; Biggs, et al., 2009). At larger calderas (>10 km diameter) deformation is frequently centred on caldera rims and extends beyond their topographic boundaries. These include displacements attributed to both magmatic and hydrothermal processes where deformation signals occur outside caldera boundaries, including at Uzon caldera, Kamchatkta (Lundgren \& Lu, 2006) and at Yellowstone, USA (Wicks et al., 2006). The peaks of displacement signals at active calderas are rarely focussed on the most recent eruption vent, although some do correspond to the location of a resurgent dome (e.g., Newman et al., 2006). 

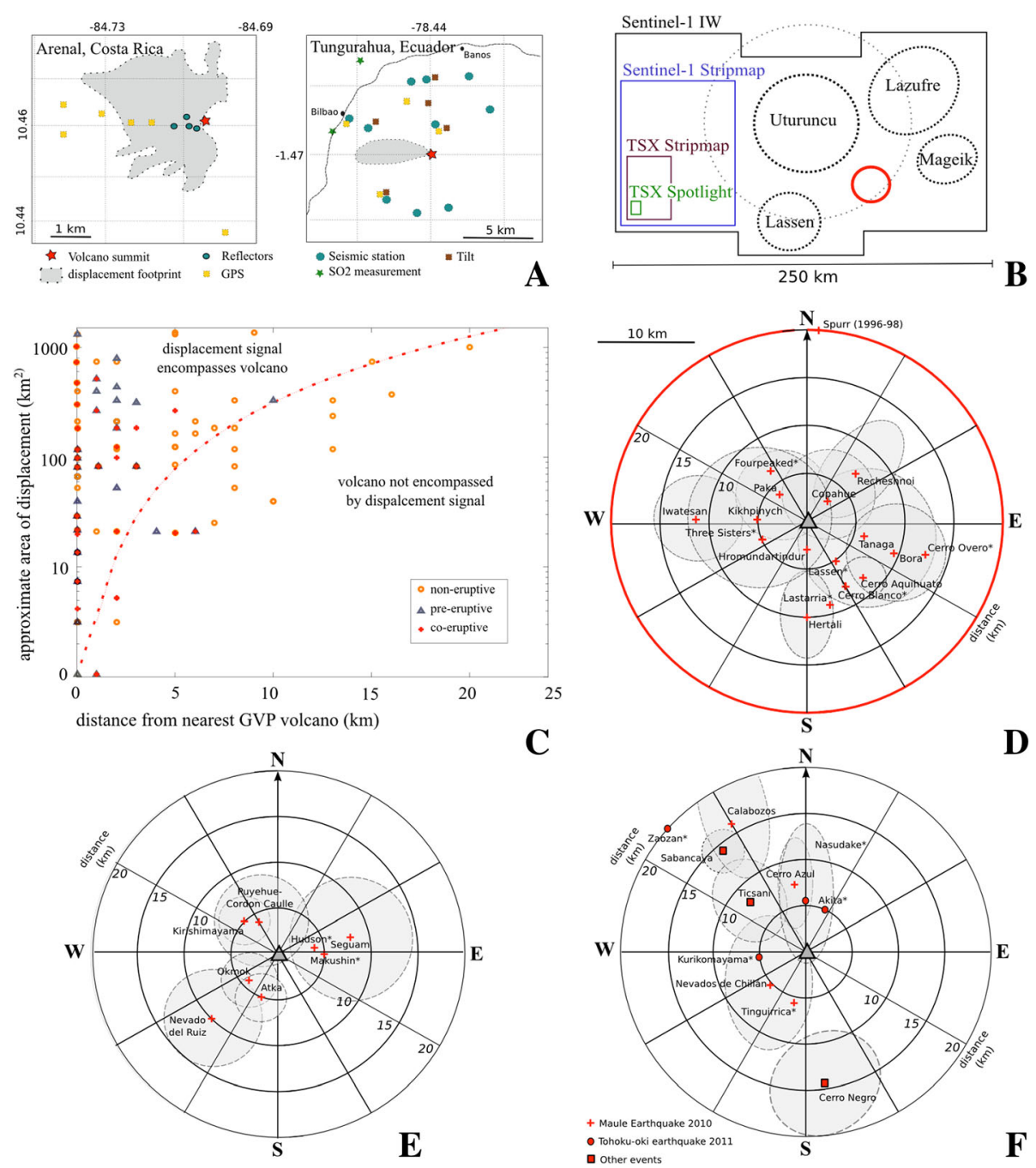

Fig. 5 a. Examples of localised displacement signals at Arenal (landsliding and gravity-driven slip) and Tungurahua (co-eruptive endogenous growth) with footprint area indicated by grey polygons and the locations of the stations that make up local monitoring networks indicated. $\mathbf{b}$. Footprints of some of the largest InSAR displacement signals detected so far compared to ground swath dimensions of commonly used SAR instruments and acquisition modes. Note that the inner footprint for Uturuncu shows uplift, while the outer footprint shows the even broader annulus of subsidence. The bold red circle (diameter $20 \mathrm{~km}$ ) indicates the size of the rose-plots in D-F. c. Scatterplot illustrating the relationship between displacement signal offsets and area. Data are limited to a single displacement episode per inferred deformation source location, so that there may be more than one entry per volcano, but only a single entry for episodes of uplift and subsidence attributed to the same source. The red dotted line describes the area of a circle with radius equal to the offset from the nearest volcano, so that points below the line generally represent displacement signals that do not encompass the nearest volcano. d. Illustration of displacement locations (red crosses) not associated with an eruption and $\geq 5 \mathrm{~km}$ from the nearest volcano (central triangle). Grey shaded ellipses show approximate signal dimensions where signal diameter $<10 \mathrm{~km}$. e. Displacement locations and footprints associated with specific eruptions, relative to the eruptive vent (central triangle), as for D. f. Displacement locations and footprints associated with earthquakes in the immediate surroundings of a volcano, or triggered by distal great earthquakes, relative to the nearest volcano (central triangle), as for D. Volcano locations are from GVP's VOTW database

For the majority (27 of 33 ) of signals occurring $\geq 5 \mathrm{~km}$ away from the nearest GVP volcano, the deformation centre is not associated with distinct volcanic structures at the surface. There are 5 cases where deformation can be associated directly with a specific eruption (Fig. 5E), and 11 either caused directly or triggered by an earthquake (Fig. 5F). In total, $24 \%$ of deformation signals attributed to magmatic deformation (32 of 133) are centred $\geq 5 \mathrm{~km}$ from the volcanic edifice, with $8 \%$ (11 of 133) more than $10 \mathrm{~km}$ away (Fig. 6A, note that only observations for which depths were available are included). Of the 11 signals $\geq 10 \mathrm{~km}$ from the volcano, Haledebi, Gelai \& Calabozos are associated with apparently young volcanic features at the surface (fresh looking lava flows, Pleistocene shield volcano \& Pleistocene collapse caldera, respectively; Biggs et al., 2011, 2013; 

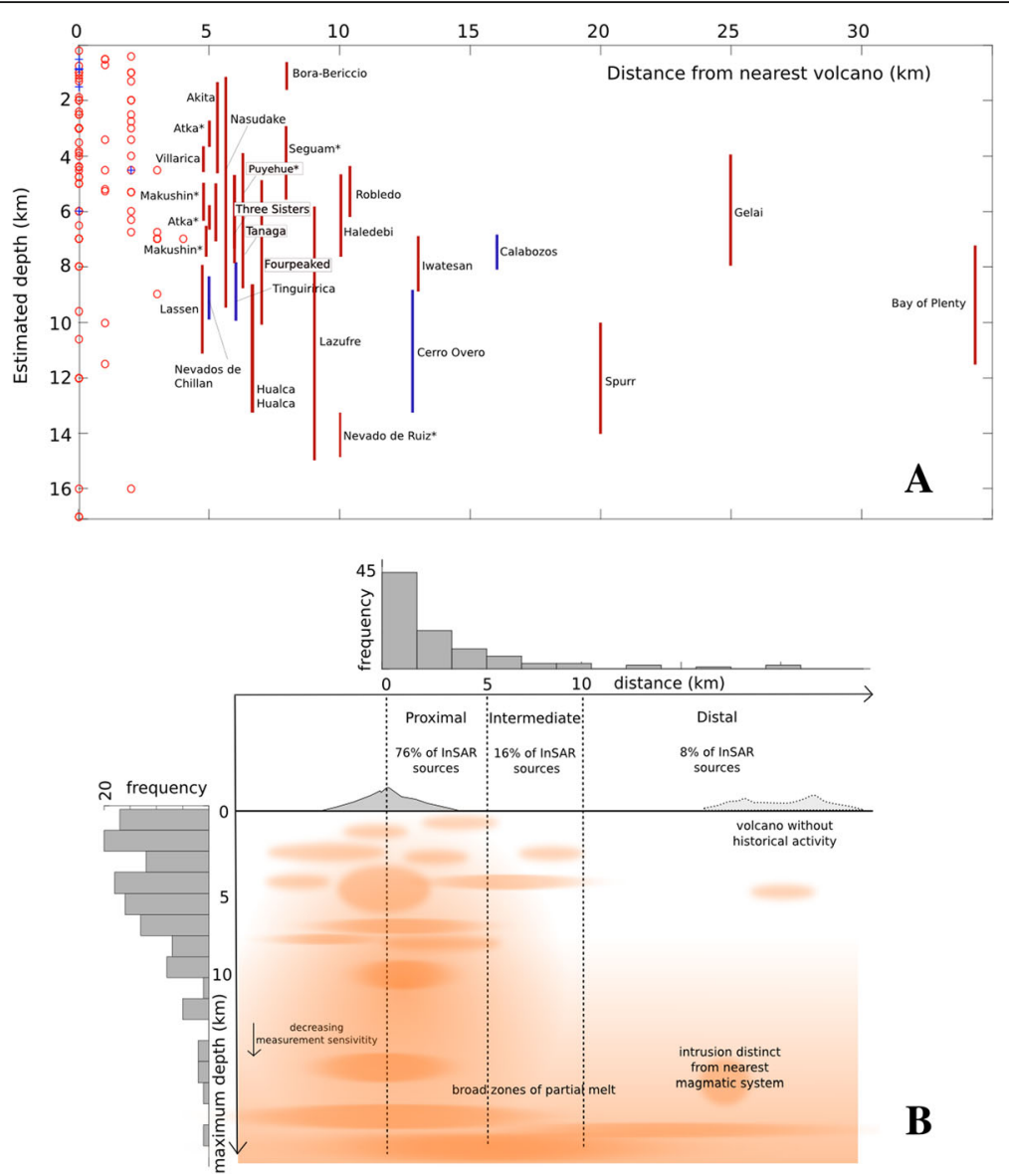

B

Fig. 6 a. Distances between the centre of deformation and the nearest edifice catalogued in the VOTW database are shown with respect to inferred source depth. For offsets greater than $\sim 5 \mathrm{~km}$, depths are shown as a range of values which correspond to the best-fit depths from different modelling methods, source geometries and time periods in different cases. Displacements $<5 \mathrm{~km}$ from the associated edifice are shown as circles. Red symbols correspond to deformation attributed to magmatic processes, while blue symbols were attributed, at least in part, to hydrothermal processes. The examples in this figure are limited to those sources interpreted to be associated with magma storage of some variety, normally modelled as a sill, point source or ellipsoid. Volcano feature locations taken from GVP's VOTW database. b. Illustration of generalised magmatic systems consistent with the prevalence of deformation sources at different lateral distances from and depths below a volcano. No vertical exaggeration

Pritchard et al., 2013). Distal uplift at Iwatesan and Spurr were both associated with seismic swarms (Nishimura et al., 2001; Lu \& Dzurisin, 2014), while uplift at the Bay of Plenty has been attributed to an off-axis pressurisation associated with the Taupo Volcanic Zone (Hamling et al., 2016). Figure 6 B is a schematic illustration of magmatic plumbing systems as we might imagine them from InSAR observations alone, and as such is likely to under-represent deeper, smaller reservoirs.

$16 \%$ of observations are between a surface radial distance of 5 and $10 \mathrm{~km}$ from the nearest volcano, and are largely at upper crustal $(<10 \mathrm{~km})$ depths. These examples are more likely to provide an indication of the lateral extent of shallow magma storage at currently active volcanoes, and where associated with eruption, have been interpreted as evidence for connections between bodies of melt-rich magma over distances exceeding $5 \mathrm{~km}$ (e.g., at Puyehue, Jay et al., 2014; Seguam, Makushin, Korovin, Lu \& Dzurisin,
2014; Kirishimayama, Kato \& Yamasato, 2013). This includes many mature caldera systems (Atka, Lu \& Dzurisin, 2014; Puyehue-Cordón Caulle, Jay et al., 2014), but also several stratovolcanoes (Three Sisters, Wicks et al., 2002; Villarica, Delgado et al., 2017 and Fourpeaked, Lu \& Dzurisin, 2014). Deformation $\geq 5 \mathrm{~km}$ from the nearest volcano is roughly half as likely to be co-eruptive (16\% of deformation $\geq 5 \mathrm{~km}$ from nearest volcano), as deformation within $5 \mathrm{~km}$ of the edifice (39\% of deformation $<5 \mathrm{~km}$ from nearest volcano).

\section{Discussion}

An implicit assumption behind the design of most instrument networks and monitoring strategies is that a persistent body of melt (a chamber) or melt-rich magma (part of a reservoir) that feeds eruptions is located directly beneath the volcanic edifice and/or active vent. This assumption is particularly common for volcanoes 
without either recent eruption or a record of unrest, and where information about subsurface plumbing is therefore minimal. The InSAR record of volcano deformation provides evidence about deformation signal characteristics that allow us to refine this at individual volcanoes, and more generally provides temporal and spatial constraints for monitoring network design, and the characteristics of deformation we can expect to detect using InSAR.

\section{Implications for the use of InSAR in volcano monitoring}

Regular acquisition strategies (e.g., Sentinel-1, COSMOSkyMed volcano background mission, ENVISAT in some parts of the world) has meant that InSAR measurements have already been used for monitoring the development of unrest or eruptions lasting weeks to years (e.g., Poland, 2014; Sigmundsson et al., 2015a, b). If satellite acquisition timings are fortuitous, InSAR may also provide important deformation information in near to real-time during a volcanic crisis, but serendipitous overflight times cannot be relied upon for monitoring. Data from multiple satellites or constellations are likely to be required for the detection of pre-eruptive deformation that occurs on similar timescales to the satellite repeat times. Given that almost one in five InSARdetected deformation episodes are thought to exceed the duration of the window over which measurements were made, the proportion of deformation episodes found to last multiple years or even decades is likely to increase in the future. The number of short duration, transient deformation episodes detected is also likely to increase due to the impact of shorter repeat time instruments and especially the application of constellations of similar satellites (e.g., COSMO-SkyMed 1-4 and Sentinel-1a,b). Improving our detection limits and establishing good baseline measurements, are also critical for being able to recognise pre-eruptive deformation.

About half of the deformation sources $\geq 5 \mathrm{~km}$ from the nearest volcano did not encompass the edifice itself. Such signals are likely to be missed by observations made from higher resolution instruments with narrower swath widths (Table 1), especially in TerraSAR-X and COSMO-SkyMed's Spotlight modes. For example, uplift southeast of Nevado del Ruiz, Colombia, was outside of the footprint of both the GPS network and the COSMO-SkyMed imagery acquired over the volcano during unrest, but was captured by RADARSAT imagery over the same time period (Lundgren et al., 2015). Observation footprints require a radius of $>20 \mathrm{~km}$ about the volcano of interest, to capture at least part of $>90 \%$ of the deformation signals in the historical InSAR catalogue. Good practice for monitoring could encompass the integration of higher resolution imagery (e.g, Spotlight mode TerraSAR-X) over active volcanoes with less frequent, broader swath imagery to identify any distal deformation processes (e.g., Sentinel-1 or ALOS-2).

\section{Considerations for recording volcanic and magmatic deformation}

The usefulness of any record of volcano deformation depends heavily on the quality of reporting. Publications from scientific journals generally provide sufficient information for measurements to be reproduced, but often lack description of signal parameters (e.g., precise location, area, discrimination between mean and maximum deformation rate). This information can often be extracted from figures, although this adds additional uncertainty associated with figure scale and labelling. Informal ('grey') literature, including conference abstracts, volcano observatory reports and personal communications may record that an observation of deformation was made, but often lack any further description. Furthermore, observations of a lack of deformation are rarely reported. An important goal of the production of catalogues and databases of volcanic and magmatic deformation is therefore to encourage community contributions of records of InSAR measurements. One purpose of this article is to engage the international community in reporting deformation to be recorded in the COMET and GVP VOTW databases.

Another consideration is the primary classification of each catalogue or database entry (Fig. 7). Episodes could be classified by deformation source location, defining a minimum spatial separation for establishing a new record, but the simplest way to do this is by volcano, which requires a common list of active volcanoes as its basis, for which the Smithsonian list of Holocene volcanoes is widely used (Global Volcanism Program 2013). This presents a particular challenge for deformation measurements, due to the notable number of episodes that have been observed at distance from Holocene volcanoes, which would nonetheless be associated with that volcano in the record (starred volcanoes in Table 2). Different deformation episodes at a volcano can be defined by their location or duration, both of which in practise depend on spatial and temporal observation windows. If properties of the deformation, beyond whether it is occurring or not, are also recorded, some further separation on the basis of signal characteristics, such as sign or rate are also required. Records by observation, rather than episode, would be needed to support future probabilistic analysis. This is challenging, because measurements of a lack of deformation are rarely reported in academic publications, so establishing a record of null results would rely on community contributions from researchers and observatory scientists.

A fully relational database is the most desirable format for recording volcano and magmatic deformation data, 


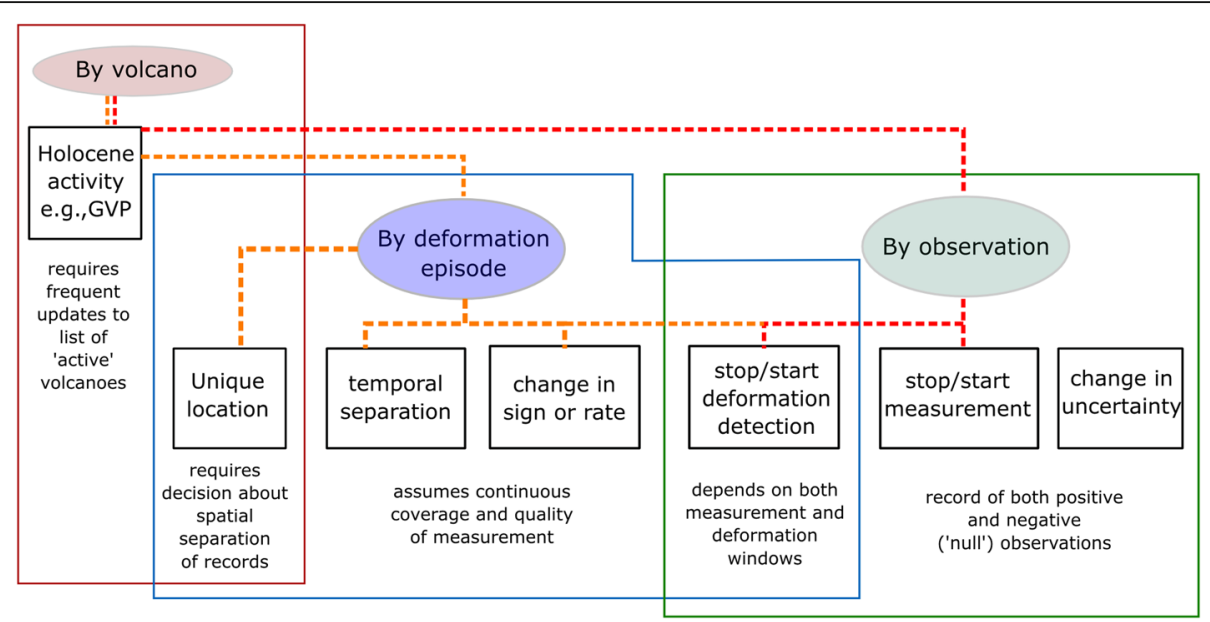

Fig. 7 Flowchart illustrating the classification choices required for recording instances of volcano deformation in a database. Both the deformation information within the GVP's VOTW database and the COMET volcano databases start by categorising by volcano using the Smithsonian list of volcanoes active in the Holocene. The GVP VOTW database (orange path) then allows the creation of separate entries for different deformation episodes. Note that although deformation episodes presented here are classified by Holocene volcano, VOTW also includes 1100 Pleistocene volcanoes, which may provide improvements for classification. Episodes are distinguished from each other on the basis of a change in location, change in sign, and temporal separation determined by either the start/stop of deformation, or the start/stop of observation. The COMET deformation catalogue (red path) aims to record InSAR observations for each volcano, with a particular emphasis on null results. In practice, both approaches result in a large number of entries that are defined by the start and end of deformation detection - a classification that depends on both timing of both observation and deformation

as it would allow future users to search for deformation episodes on the basis of location, as well as properties such as rate, duration, area or inferred depth. However, the construction of a database requires defining categories that impose some interpretation on observations. For example, recording a deformation rate, requires that a new entry is made every time a new rate is measured. Similarly, periodic pulses of uplift and subsidence attributed to the same source would require multiple database entries. A suitable approach at least for preliminary catalogue entries, is to allow a 'free text' format, so that as much information can be recorded as possible, allowing for unexpected styles of deformation that do not conform to previously established definitions. This also allows for a description of uncertainty, which would currently be challenging to define uniformly for InSAR measurements due to the diversity of data, processing and analysis methods widely used. However, community contributions provided in this manner are likely to vary in consistency more than entries to a database with clear definitions. The paths taken to describe deformation by GVP's VOTW database (orange) and COMET deformation catalogue (red) drawn upon here, are indicated on the flowchart in Fig. 7, which shows the areas of overlap and difference between the two approaches. A further consideration for the dissemination of InSAR data is the challenge of storing and sharing the very large data files. The seismic community generally share event catalogues in the first instance, and an analogous approach for InSAR may be to share deformation signal parameters or heavily downsampled data.

\section{Characteristics of shallow magmatic domains}

InSAR measurements allow us to identify distinct sites of magma storage at high spatial resolution. As relatively few magmatic systems have been imaged tomographically (e.g., Lees, 2007; Sigmundsson, 2016), at many volcanoes this provides the best evidence of the lateral extent of many active magmatic domains. The decrease in the number of deformation sources found with increasing depth (e.g., Figure 6) may reflect a transition away from elastic rheology, but is also a consequence of measurement detection thresholds (i.e., deep sources will only cause measurable deformation if volume changes are very large). The lateral distribution of sources, however, is not correlated to systematic measurement uncertainty or modelling choices, and is therefore expected to capture real characteristics of magmatic systems. Laterally extensive magmatic domains encompassing multiple deformation sources (Figure 6) are consistent with the upper levels of a complex, variable melt fraction system (e.g., Cashman et al., 2017). Mechanisms for deformation in such systems include the ascent and intrusion of juvenile magma, the migration of mobile melt/volatiles and phase transitions (e.g., crystallisation, exsolution).

Broad zones of magma storage have previously been identified by tomographic studies that found low velocity 
zones $>10 \mathrm{~km}$ in diameter beneath active volcanoes (e.g., Lees, 2007) and by magnetotelluric studies (e.g., Aoki et al., 2013) that have detected large conductive bodies up to $20 \mathrm{~km}$ away from the locations of recent eruptions. Calderas where the manifestations of unrest (e.g., seismicity, thermal anomalies, fumerolic gas emission) extend over a large area are expected to sit over large, complex magmatic domains (e.g., Wicks et al., 2006). InSAR observations of laterally offset deformation at some stratovolcanoes (e.g., Delgado et al., 2017) have provided new evidence of magmatic domain extent at smaller, younger volcanoes. Deformation associated with an eruption is more likely to be 'central' $(<5 \mathrm{~km}$ from the volcano) than 'offset' ( $\geq 5 \mathrm{~km}$ distant), although there are a few notable examples of distal deformation accompanying eruption (e.g., Jay et al., 2014). 'Offset' deformation not associated with eruptions have been attributed to both magmatic and hydrothermal processes (notably, Pritchard et al., 2013 and Takada and Fukushima, 2013), so distinguishing between these origins at upper crustal depths is an important problem for understanding the shape and characteristics of magmatic domains.

That $\sim 24 \%$ of potentially magmatic InSAR signals are centred over $5 \mathrm{~km}$ from the nearest volcano demonstrates that laterally extensive active magmatic zones are not exceptional. Such 'offset' deformation sources have so far been found in both rift zones and volcanic arcs, and at volcanoes with a range of maturities. We expect melt-rich lenses to be localised in zones with favourable stress conditions in volcanic arcs, in contrast to rift zones where high melt fractions are likely to extend over larger areas. This suggests that locations of deformation will vary more in rift zones than in volcanic arcs, where stress conditions may favour persistent magma reservoirs. Seismic reflection and field observations suggest that felsic sill complexes have total lateral extents of $<20 \mathrm{~km}$, while shallow complexes of mafic sills may have much greater lateral extents (e.g., Magee et al., 2016). This suggests that there are likely to be major differences in the eventual geometry and extent of mature magmatic domains in different tectonics settings and for different magma compositions. The increasing total duration of global InSAR coverage will provide data with which to examine variations between active systems, as well as the impact of differences in melt supply and magmatic system maturity.

\section{Conclusions}

Analysis of SAR images and InSAR measurements of deformation are increasingly used in volcano monitoring, and are swelling the number of geodetically monitored subaerial volcanoes, improving the spatial resolution of routine observations and contributing to our understanding of the diversity of 'pre- eruptive' deformation signals. We consider a reliable and detailed record of past observations of volcanic and magmatic deformation - preferably incorporating uncertainties and description of 'null' results - to be essential for the future interpretation of interferograms in volcanic settings. Our synthesis of global InSAR measurements of volcanic and magmatic deformation has implications both for the design of volcano monitoring strategies and for our understanding of the distribution of magma in the crust.

We use the historical InSAR catalogue as a 'baseline' for assessing the contexts for which SAR is most useful for monitoring applications. Deformation lasting more than a few months, but less than a decade is best represented in the InSAR records, with spatial extents of hundreds of metres to hundreds of kilometres. However, the number of deformation episodes that are (1) transient, lasting days or less and not producing permanent deformation, (2) at magnitudes of a few mm per year and (3) located several kilometres from the nearest volcano may be underrepresented. The combination of data from multiple satellites or constellations, longer total duration of satellite missions and use of broad survey-mode regional measurements can mitigate these gaps for future monitoring.

Of the InSAR deformation signals attributed to magmatic processes, $24 \%$ are centred at distances $\geq 5 \mathrm{~km}$ from the nearest active volcano, and most have sources in the shallow crust $(<10 \mathrm{~km}$ depth). Such 'offset' deformation fields, many of which encompass the volcano, are found across different tectonic settings and include co-eruptive subsidence, episodes of uplift, and subsidence triggered by great earthquakes. This constitutes independent evidence that magmatic processes take place over broad regions of the shallow crust (at least over many 10s of kilometres) at many volcanoes, and is consistent with a vision of magmatic processes that incorporates spatially complex, dynamic zones of varying crystal, melt and volatile fraction. Future analysis of the global set of InSAR measurements have potential to provide useful constraints on the characteristics of the shallowest parts of trans-crustal magmatic systems.

\section{Endnotes}

${ }^{1}$ We use the term 'volcano observatory' to refer to organizations with statutory responsibilities that include monitoring volcanic hazards. In different countries this may be a national geological survey or meteorological office, an academic institution, or branch of the civil service.

${ }^{2}$ The initial public release of the deformation data on 31 March 2017 was updated to add figures and references on 8 May 2017 (VOTW version 4.5.6, unchanged with the 4.6 update) 


\section{Appendix 1}

Contributor Guidelines for the COMET deformation database as they appear on:

volcanodeformation.blogs.ilrt.org/how-to-submit-anentry

Volcano name, Volcano number, Latitude and Longitude should be as they appear in the Smithsonian Database (download the 'Holocene Spreadsheet' from the Database menu, here). In the case of deformation not clearly associated with a particular volcanic edifice, assign it to the nearest edifice and make this clear in the Characteristics of Deformation box, including latitude and longitude of the centre of deformation. Please take particular care with volcanoes that have non-unique names - check that the Volcano number, Latitude and Longitude all match the Smithsonian Database.

Under Geodetic measurements, select 'Yes' for cases where deformation measurements have been made, and 'No' if there have never been any measurements. If there have been geodetic measurements and deformation of the volcano was shown, the field Deformation Detected should be set to 'Yes'. This should only set to 'No' if there have been geodetic measurements that have not demonstrated deformation.

For the Measurement Method(s) check boxes, please tick as many as apply. Make sure to record the time periods covered by each measurement method and any differences in the type of deformation measured in the Characteristics of Deformation section. If you enter text into the 'Other' box it will appear on the website exactly as you type it, so make sure that it is phrased clearly and concisely.

Please indicate the Duration of Observations using dates $(M M / Y Y Y Y)$ separated by a hyphen. If measurements were made over several discrete periods please list these separated by a comma, e.g. 05/2007-08/2007, 01/ 2008-10/2009.

Choose as many Inferred Causes of Deformation as you judge to apply. For more information about the categories we use here, read this section. If you enter text into the 'Other' box it will appear on the website exactly as you type it, so make sure that it is phrased clearly and concisely.

The Characteristics of Deformation box should contain information about all of the observations of deformation, their interpretation and results from modelling. This should be as quantitative as possible and include references (format: Anon et al., 2014). The information contained here will of course vary significantly between volcanoes, but please use the points below as a checklist. You may need to address each point for multiple measurement techniques or periods of observation. Make sure to use SI units and appropriate references in this section.
- Where is the deformation? If not centred on the volcano, please provide lat/lon. What is the diameter of the deformation? Describe the spatial deformation pattern and how it relates to the volcano?

- How long did deformation last? Has there been more than one deformation event?

- Give a qualitative description of the character of the deformation. Was it steady, episodic or transient? Uplift or subsidence?

- Provide quantitative information about the character of deformation to back up your description. What was its rate? By how much does it vary? How many pulses of deformation have been measured? etc.

- Has a deformation source been inferred? What is the best-fit source for the deformation? What is the uncertainty on this? How deep is the source (with what uncertainty)? What is the volume change of the deformation source (with what uncertainty)?

You can add up to five References for each volcano (one reference is compulsory). Please include all author names and don't use abbreviations in the title or journal name. If the article has a doi, please use it and where possible turn it into a hyperlink.

\section{Additional file}

Additional file 1: Table S1. Supplementary table summarising the spatial and temporal characteristics ofdefomation signals discussed in this article. Notes on estimated source depth and relevant citations are also included. For full references, and a more detailed summary of past observations, please refer to the VOTW deformation database and to the COMET volcano deformation catalogue. (XLSX $46 \mathrm{~kb}$ )

\section{Acknowledgments}

Funding

SKE is funded by a Leverhulme Early Career Fellowship and a European Space Agency Living Planet fellowship (formerly held at the University of Bristol) co-funded by the NERC-BGS Centre for the Observation and Modelling of Earthquakes, Volcanoes and Tectonics (COMET). JB is also funded by COMET and by NERC grant Strengthening Resilience in Volcanic Areas (STREVA, NE/J020052/1). The development of the COMET deformation catalogue was supported by a NERC Impact Acceleration Account from the University of Bristol. J.A.J., M.A.F and M.E.P. were partly supported by NASA grants NNX12AO31G and NNX12AM24G issued through the Science Mission Directorate's Earth Science Division. J.A.J. was also partly supported by a postdoctoral fellowship from the Smithsonian Institution Global Volcanism Program. EC is grateful for support from the Deep Carbon Observatory.

\section{Availability of data and materials}

Unless otherwise stated, the observations discussed in this article are drawn from the Smithsonian Institution Global Volcanism Programs Volcanoes of the World database (volcano.si.edu) and the NERC-BGS Centre for the

Observation and Modelling of Earthquakes, Volcanoes and Tectonics Volcano Deformation Database (volcanodeformation.blogs.ilrt.org).

\section{Authors' contributions}

S.K.E. wrote the paper, compiled information about spatial characteristics of deformation signals and, with J.B., designed and initiated the COMET volcano deformation database. J.J., M.F., M.E.P., B.J.A., E.V., and E.C. designed the deformation component of the VOTW database and contributed database entries. A.L.P., D.W.D.A., R.L., J.H., E.R., M.C.A., C.C. and J.L.W. 
contributed entries to the COMET volcano deformation database. All authors read and approved the final manuscript.

\section{Authors' information}

Not applicable.

\section{Competing interests}

None of the authors have financial or non-financial competing interests in this manuscript.

\section{Publisher's Note}

Springer Nature remains neutral with regard to jurisdictional claims in published maps and institutional affiliations.

\section{Author details \\ ${ }^{1}$ School of Earth \& Environment, University of Leeds, Leeds LS2 9JT, UK. ${ }^{2}$ Global Volcanism Program, National Museum of Natural History, Smithsonian Institution, Washington DC, USA. ${ }^{3}$ COMET, University of Bristol, Wills Memorial Building, Queens Road, Bristol BS8 1RJ, UK. ${ }^{4}$ School of Geography, University of Leeds, Leeds LS2 9JT, UK. 'Department of Earth, Environmental and Planetary Sciences, Rice University, Houston, TX 77005, USA. ${ }^{6}$ Camborne School of Mines, University of Exeter, Cornwall TR10 9FE, UK. ${ }^{7}$ Department of Spatial Sciences and The Institute for Geoscience Research, Curtin University, GPO Box U1987, Perth, WA 6845, Australia. ${ }^{8}$ Department of Earth and Atmospheric Sciences, Snee Hall, Cornell University, Ithaca, NY 14853, USA.}

\section{Received: 4 August 2017 Accepted: 9 January 2018}

\section{Published online: 06 February 2018}

\section{References}

Albino F, Smets B, d'Oreye N, Kervyn F. High resolution TanDEM-X DEM: an accurate method to estimate lava flow volumes at Nyamulagira volcano (DR Congo). J Geophys Res Solid Earth. 2015;120(6):4189-207.

Amelung F, Jónsson S, Zebker H, Segall P. Widespread uplift and 'trapdoor' faulting on Galapagos volcanoes observed with radar interferometry. Nature. 2000;407(6807):993-6.

Amoruso, A., \& Crescentini, L. (2009). Shape and volume change of pressurized ellipsoidal cavities from deformation and seismic data. Journal of Geophysical Research: Solid Earth, 114(B2).

Aoki Y, Takeo M, Ohminato T, Nagaoka Y, Nishida K. Magma pathway and its structural controls of Asama volcano, Japan. Geol Soc Lond, Spec Publ. 2013; 380(1):67-84.

Arnold DWD, Biggs J, Wadge G, Ebmeier SK, Odbert HM, Poland MP. Dome growth, collapse, and valley fill at Soufrière Hills volcano, Montserrat, from 1995 to 2013: contributions from satellite radar measurements of topographic change. Geosphere. 2016;12(4):1300-15.

Arnold DWD, Biggs J, Anderson K, Vargas SV, Wadge G, Ebmeier SK, Naranjo MF, and Mothes P (2017), Decaying lava extrusion rate at El Reventador Volcano, Ecuador measured using high-resolution satellite radar, J. Geophys. Res., 122, doi:https://doi.org/10.1002/2017JB014580.

Bagnardi M, Amelung F, Poland MP. A new model for the growth of basaltic shields based on deformation of Fernandina volcano, Galápagos Islands. Earth Planet Sci Lett. 2013;377:358-66.

Bekaert DPS, Walters RJ, Wright TJ, Hooper AJ, Parker DJ. Statistical comparison of InSAR tropospheric correction techniques. Remote Sens Environ. 2015;170:40-7.

Biggs J, Pritchard ME. Global volcano monitoring: what does it mean when volcanoes deform? Elements. 2017;13(1):17-22.

Biggs J, Amelung F, Gourmelen N, Dixon TH, Kim SW. InSAR observations of 2007 Tanzania rifting episode reveal mixed fault and dyke extension in an immature continental rift. Geophys J Int. 2009;179(1):549-58.

Biggs, J., Mothes, P., Ruiz, M., Amelung, F., Dixon, T. H., Baker, S., \& Hong, S. H. (2010a). Stratovolcano growth by co-eruptive intrusion: The 2008 eruption of Tungurahua Ecuador. Geophysical Research Letters, 37(21).

Biggs, J., Lu, Z., Fournier, T., \& Freymueller, J. T. (2010b). Magma flux at Okmok Volcano, Alaska, from a joint inversion of continuous GPS, campaign GPS, and interferometric synthetic aperture radar. Journal of Geophysical Research: Solid Earth, 115(B12).

Biggs J, Bastow ID, Keir D, Lewi E. Pulses of deformation reveal frequently reccurring shallow magmatic activity beneath the main Ethiopian rift. Geochem Geophys Geosyst. 2011;12:9.
Biggs J, Chivers M, Hutchinson MC. Surface deformation and stress interactions during the 2007-2010 sequence of earthquake, dyke intrusion and eruption in northern Tanzania. Geophys J Int. 2013;195(1):16-26.

Biggs, J., Ebmeier, S. K., Aspinall, W. P., Lu, Z., Pritchard, M. E., Sparks, R. S. J., \& Mather, T. A. (2014). Global link between deformation and volcanic eruption quantified by satellite imagery. Nature communications, 5 .

Biggs J, Robertson E, Cashman K. The lateral extent of volcanic interactions during unrest and eruption. Nat Geosci. 2016;9(4):308-11.

Brown SK, Crosweller HS, Sparks RSJ, Cottrell E, Deligne NI, Guerrero NO, Hobbs L, Kiyosugi K, Loughlin SC, Siebert L, Takarada S. Characterisation of the quaternary eruption record: analysis of the large magnitude explosive volcanic eruptions (LaMEVE) database. J Appl Volcanol. 2014;3(1):1-22.

Brunori CA, Bignami C, Stramondo S, Bustos E. 20 years of active deformation on volcano caldera: Joint analysis of InSAR and AlnSAR techniques. Int J Appl Earth Obs Geoinf. 2013;23:279-87.

Buongiorno, M.F., Musacchio, M., Vignoli, S., Zoffoli, S., Amodio, A., Cardaci, C., Pugnaghi, S., Teggi, S., Sansosti, E., Puglisi, G. and Borgstrom, S., 2008. Volcanic risk system (SRV): ASI pilot project to support the monitoring of volcanic risk in Italy by means of EO data. In Use of Remote Sensing Techniques for Monitoring Volcanoes and Seismogenic Areas, 2008. USEReST 2008. Second Workshop on (pp. 1-5). IEEE.

Bürgmann R, Rosen PA, Fielding EJ. Synthetic aperture radar interferometry to measure Earth's surface topography and its deformation. Annu Rev Earth Planet Sci. 2000;28(1):169-209.

Caricchi L, Biggs J, Annen C, Ebmeier SK. The influence of cooling, crystallisation and re-melting on the interpretation of geodetic signals in volcanic systems. Earth Planet Sci Lett. 2014;388:166-74.

Cashman, K. V., Sparks, R. S. J., \& Blundy, J. D. (2017). Vertically extensive and unstable magmatic systems: A unified view of igneous processes. Science, 355(6331).

Chaussard E, Amelung F. Regional controls on magma ascent and storage in volcanic arcs. Geochem Geophys Geosyst. 2014;15(4):1407-18.

Chaussard E, Amelung F, Aoki Y. Characterization of open and closed volcanic systems in Indonesia and Mexico using InSAR time series. J Geophys Res Solid Earth. 2013;118(8):3957-69.

Delgado F, Pritchard M, Lohman R, Naranjo JA. The 2011 Hudson volcano eruption (southern Andes, Chile): pre-eruptive inflation and hotspots observed with InSAR and thermal imagery. Bull Volcanol. 2014;76(5):815.

Delgado F, Pritchard ME, Basualto D, Lazo J, Córdova L, Lara LE. Rapid reinflation following the 2011-2012 rhyodacite eruption at Cordón Caulle volcano (Southern Andes) imaged by InSAR: Evidence for magma reservoir refill. Geophys Res Lett. 2016;43(18):9552-62.

Delgado, F., Pritchard, M. E., Ebmeier, S., González, P., \& Lara, L. (2017). Recent unrest (2002-2015) imaged by space geodesy at the highest risk Chilean volcanoes: Villarrica, Llaima, and Calbuco (Southern Andes). Journal of Volcanology and Geothermal Research.

Dietterich HR, Poland MP, Schmidt DA, Cashman KV, Sherrod DR, Espinosa AT. Tracking lava flow emplacement on the east rift zone of Kilauea, Hawai'i, with synthetic aperture radar coherence. Geochem Geophys Geosyst. 2012; 13(5)

Diez M, La Femina PC, Connor CB, Strauch W, Tenorio V. Evidence for static stress changes triggering the 1999 eruption of Cerro Negro volcano, Nicaragua and regional aftershock sequences. Geophys Res Lett. 2005;32(4)

Dzurisin D. Volcano geodesy: challenges and opportunities for the 21st century. Philosophical transactions of the Royal Society of London a: mathematical. Phys Eng Sci. 2000;358(1770):1547-66.

Dzurisin D, Lisowski M, Wicks CW. Continuing inflation at Three Sisters volcanic center, central Oregon Cascade Range, USA, from GPS, leveling, and InSAR observations. Bull Volcanol. 2009;71(10):1091-110.

Ebmeier SK. Application of independent component analysis to multitemporal InSAR data with volcanic case studies, J. Geophys. Res. Solid Earth. 2016;121: 8970-86. https://doi.org/10.1002/2016JB013765.

Ebmeier, S. K., Biggs, J., Mather, T. A., Wadge, G., \& Amelung, F. (2010). Steady downslope movement on the western flank of Arenal volcano, Costa Rica. Geochemistry, Geophysics, Geosystems, 11(12).

Ebmeier SK, Biggs J, Mather TA, Elliott JR, Wadge G, Amelung F. Measuring large topographic change with InSAR: lava thicknesses, extrusion rate and subsidence rate at Santiaguito volcano, Guatemala. Earth Planet Sci Lett. 2012;335:216-25.

Ebmeier SK, Biggs J, Mather TA, Amelung F. Applicability of InSAR to tropical volcanoes: insights from central America. Geol Soc Lond, Spec Publ. 2013; 380(1):15-37 
Ebmeier SK, Biggs J, Muller C, Avard G. Thin-skinned mass-wasting responsible for widespread deformation at Arenal volcano. Front Earth Sci. 2014;2:35.

Ebmeier SK, Elliott JR, Nocquet JM, Biggs J, Mothes P, Jarrín P, Yépez M, Aguaiza S, Lundgren P, Samsonov SV. Shallow earthquake inhibits unrest near ChilesCerro Negro volcanoes, Ecuador-Colombian border. Earth Planet Sci Lett. 2016;450:283-91.

Elliott, J. R., R. J. Walters \& T. J. Wright (2016). The role of space-based observation in understanding and responding to active tectonics and earthquakes, Nature Communications, 7, doi:https://doi.org/10.1038/ncomms13844.

Fearnley CJ, McGuire WJ, Davies G, Twigg J. Standardisation of the USGS Volcano Alert Level System (VALS): analysis and ramifications. Bull Volcanol. 2012;74(9): 2023-36.

Feigl KL, Le Mével H, Ali ST, Córdova L, Andersen NL, DeMets C, Singer BS. Rapid uplift in Laguna del Maule volcanic field of the Andean southern volcanic zone (Chile) 2007-2012. Geophys J Int. 2014;196(2):885-901.

Fournier, T. J., Pritchard, M. E., \& Riddick, S. N. (2010). Duration, magnitude, and frequency of subaerial volcano deformation events: New results from Latin America using InSAR and a global synthesis. Geochemistry, Geophysics, Geosystems, $11(1)$.

Froger JL, Merle O, Briole P. Active spreading and regional extension at Mount Etna imaged by SAR interferometry. Earth Planet Sci Lett. 2001; 187(3):245-58.

Froger J-L, Remy D, Bonvalot S, Legrand D. Two scales of inflation at LastarriaCordon del Azufre volcanic complex, central Andes, revealed from ASARENVISAT interferometric data. Earth Planet Sci Lett. 2007;255(1-2):148-63.

Global Volcanism Program, 2013. Venzke, E (ed.)., Volcanoes of the World, v. 4.6.0. Smithsonian Institution. Downloaded 19 Jun 2017. https://doi.org/10.5479/si. GVP.VOTW4-2013

Gong W, Meyer FJ, Lee C-W, Lu Z, Freymueller J. Measurement and interpretation of subtle deformation signals at Unimak Island from 2003 to 2010 using weather model-assisted time series InSAR. J Geophys Res Solid Earth. 2015; 120(2):1175-94

González PJ, Samsonov SV, Pepe S, Tiampo KF, Tizzani P, Casu F, Fernández J, Camacho AG, Sansosti E. Magma storage and migration associated with the 2011-2012 el Hierro eruption: implications for crustal magmatic systems at oceanic island volcanoes. J Geophys Res Solid Earth. 2013;118(8):4361-77.

Gottsmann J, Folch A, Rymer H. Unrest at Campi Flegrei: a contribution to the magmatic versus hydrothermal debate from inverse and finite element modelling. J Geophys Res Solid Earth. 2006;111(B7)

Gudmundsson MT, Jónsdóttir K, Hooper A, Holohan EP, Halldórsson SA Ófeigsson BG, Cesca S, Vogfjörd KS, Sigmundsson F, Högnadóttir T, Einarsson P. Gradual caldera collapse at Bárdarbunga volcano, Iceland, regulated by lateral magma outflow. Science. 2016;353(6296):aaf8988.

Hamling IJ, Wright TJ, Calais E, Bennati L, Lewi E. Stress transfer between thirteen successive dyke intrusions in Ethiopia. Nat Geosci. 2010;3(10):713-7.

Hamling IJ, Hreinsdottir S, Fournier N. The ups and downs of the TVZ: geodetic observations of deformation around the Taupo volcanic zone, New Zealand. J Geophys Res Solid Earth. 2015;120(6):4667-79.

Hamling IJ, Hreinsdóttir S, Bannister S, Palmer N. Off-axis magmatism along a subaerial back-arc rift: observations from the Taupo volcanic zone, New Zealand. Sci Adv. 2016;2(6):e1600288.

Heise, W., H. M. Bibby, T. Grant Caldwell, S. C. Bannister, Y. Ogawa, S. Takakura, T. Uchida. (2007). Melt distribution beneath a young continental rift: The Taupo Volcanic Zone, New Zealand. Geophys. Res. Lett. 34,

Henderson ST, Pritchard ME. Decadal volcanic deformation in the Central Andes volcanic zone revealed by InSAR time series. Geochem Geophys Geosyst. 2013;14(5):1358-74.

Hickey J, Gottsmann J. Benchmarking and developing numerical Finite Element models of volcanic deformation. J Volcanol Geotherm Res. 2014;280:126-30.

Hooper, A. (2008). A multi-temporal InSAR method incorporating both persistent scatterer and small baseline approaches. Geophysical Research Letters, 35(16).

Hreinsdóttir S, Sigmundsson F, Roberts MJ, Björnsson H, Grapenthin R, Arason P, Árnadóttir T, Hólmjárn J, Geirsson H, Bennett RA, Gudmundsson MT, Oddsson B, Ófeigsson BG, Villemin T, Jónsson T, Sturkell E, Höskuldsson Á, Larsen G, Thordarson T, Óladóttir BA. Volcanic plume height correlated with magmapressure change at Grimsvotn Volcano, Iceland. Nat Geosci. 2014a; 7(3):214-8.

Jay J, Costa F, Pritchard ME, Lara L, Singer B, Herrin J. Locating magma reservoirs using InSAR and petrology before and during the 2011-2012 Cordón Caulle silicic eruption. Earth Planet Sci Lett. 2014;395:254-66.
Jónsson S. Stress interaction between magma accumulation and trapdoor faulting on sierra Negra volcano, Galápagos. Tectonophysics. 2009;471(1):3644.

Jónsson S, Zebker H, Cervelli P, Segall P, Garbeil H, Mouginis-Mark P, Rowland S. A shallow-dipping dike fed the 1995 flank eruption at Fernandina Volcano, Galapagos, observed by satellite radar interferometry. Geophys Res Lett. 1999;26(8):1077-80.

Kato K, Yamasato H. The 2011 eruptive activity of Shinmoedake volcano, Kirishimayama, Kyushu, Japan—overview of activity and volcanic alert level of the Japan meteorological agency - Earth, Planets and Space. 2013;65(6): 489-504.

Le Mével H, Feigl KL, Córdova L, DeMets C, Lundgren P. Evolution of unrest at Laguna del Maule volcanic field (Chile) from InSAR and GPS measurements, 2003 to 2014. Geophys Res Lett. 2015;42(16):6590-8.

Lee CW, Lu Z, Won JS, Jung HS, Dzurisin D. Dynamic deformation of Seguam Island, Alaska, 1992-2008, from multi-interferogram InSAR processing. J Volcanol Geotherm Res. 2013;260:43-51.

Lees JM. Seismic tomography of magmatic systems. J Volcanol Geotherm Res. 2007;167(1):37-56

Lénat JF, Bachèlery P, Peltier A. The interplay between collapse structures, hydrothermal systems, and magma intrusions: the case of the central area of piton de la Fournaise volcano. Bull Volcanol. 2012;74(2):407-21.

López, C., M. J. Blanco, R. Abella, B. Brenes, V. M. Cabrera Rodríguez, B. Casas, I. Domínguez Cerdeña et al. (2012). "Monitoring the volcanic unrest of El Hierro (Canary Islands) before the onset of the 2011-2012 submarine eruption." Geophysical Research Letters 39, no. 13.

Loughlin, S. C., Sparks, S., Brown, S. K., Vye-Brown, C., \& Jenkins, S. F. (Eds.). (2015). Global volcanic hazards and risk. Cambridge University Press.

Lu, Z. and Dzurisin, D., 2014. InSAR imaging of Aleutian volcanoes: monitoring a volcanic arc from space. Springer Science \& Business Media.

Lu, Z., Dzurisin, D., Biggs, J., Wicks, C., \& McNutt, S. (2010). Ground surface deformation patterns, magma supply, and magma storage at Okmok volcano, Alaska, from InSAR analysis: 1. Intereruption deformation, 1997 „Äi2008. Journal of Geophysical Research: Solid Earth (1978-2012), 115(B5).

Lundgren, P., \& Lu, Z. (2006). Inflation model of Uzon caldera, Kamchatka, constrained by satellite radar interferometry observations. Geophysical Research Letters, 33(6).

Lundgren P, Usai S, Sansosti E, Lanari R, Tesauro R, Fornaro G, Berardino P. Modeling surface deformation observed with synthetic aperture radar Interferometry at Campi Flegrei caldera. J Geophys Res Solid Earth. 2001; 106(B9):19355-66.

Lundgren, P., Casu, F., Manzo, M., Pepe, A., Berardino, P., Sansosti, E., \& Lanari, R. (2004). Gravity and magma induced spreading of Mount Etna volcano revealed by satellite radar interferometry. Geophysical Research Letters, 31(4).

Lundgren P, Samsonov SV, López Velez CM, Ordoñez M. Deep source model for Nevado del Ruiz volcano, Colombia, constrained by interferometric synthetic aperture radar observations. Geophys Res Lett. 2015;42(12):4816-23.

Magee C, Muirhead JD, Karvelas A, Holford SP, Jackson CAL, Bastow ID, Schofield $\mathrm{N}$, Stevenson CTE, McLean C, McCarthy W, Shtukert O. Lateral magma flow in mafic sill complexes. Geosphere. 2016;12(3):809-41.

Masterlark, T. (2007). Magma intrusion and deformation predictions: Sensitivities to the Mogi assumptions. Journal of Geophysical Research: Solid Earth, 112(B6).

Masterlark T, Lu Z. Transient volcano deformation sources imaged with interferometric synthetic aperture radar: Application to Seguam Island, Alaska. J Geophys Res Solid Earth. 2004;109:B01401.

Mastin LG, Roeloffs E, Beeler NM, Quick JE. Constraints on the size, overpressure, and volatile content of the Mount St. Helens magma system from geodetic and dome-growth measurements during the 2004-2006+ eruption. A volcano rekindled: the renewed eruption of Mount St. Helens, 2004-2006; 2008. p. 461-78.

McCormick Kilbride B, Edmonds M, Biggs J. Observing eruptions of gas-rich compressible magmas from space. Nat Commun. 2016;7

Meyer FJ, McAlpin DB, Gong W, Ajadi O, Arko S, Webley PW, Dehn J. Integrating SAR and derived products into operational volcano monitoring and decision support systems. ISPRS J Photogramm Remote Sens. 2015;100:106-17.

Miyagi Y, Ozawa T, Kozono T, Shimada M (2013) DInSAR/PSInSAR Observations of Kirishima, Shinmoe-dake Volcano, Japan. EGU General Assembly abstract EGU2013-4658, Vienna, Austria.

Morales Rivera AM, Amelung F, Mothes P. Volcano deformation survey over the Northern and Central Andes with ALOS InSAR time series. Geochem Geophys Geosyst. 2016;17(7):2869-83. 
Moran SC, Kwoun O, Masterlark T, Lu Z. On the absence of InSAR-detected volcano deformation spanning the 1995-1996 and 1999 eruptions of Shishaldin volcano, Alaska. J Volcanol Geotherm Res. 2006;150(1):119-31.

Naranjo MF, Ebmeier SK, Vallejo S, Ramón P, Mothes P, Biggs J, Herrera F. Mapping and measuring lava volumes from 2002 to 2009 at el Reventador volcano, Ecuador, from field measurements and satellite remote sensing. J Appl Volcanol. 2016;5(1):1-11.

Neri, M., Casu, F., Acocella, V., Solaro, G., Pepe, S., Berardino, P., Sansosti, E. Caltabiano, T., Lundgren, P. and Lanari, R., 2009. Deformation and eruptions at Mt. Etna (Italy): a lesson from 15 years of observations. Geophysical Research Letters, 36(2).

Newman AV, Dixon TH, Gourmelen N. A four-dimensional viscoelastic deformation model for Long Valley caldera, California, between 1995 and 2000. J Volcanol Geotherm Res. 2006;150(1):244-69.

Nishimura T, Fujiwara S, Murakami M, Tobita M, Nakagawa H, Sagiya T, Tada T. The M6.1 earthquake triggered by volcanic inflation of Iwate Volcano, northern Japan, observed by satellite radar interferometry. Geophys Res Lett. 2001;28(4):635-8.

Osmanoğlu B, Sunar F, Wdowinski S, Cabral-Cano E. Time series analysis of InSAR data: methods and trends. ISPRS J Photogramm Remote Sens. 2016;115:90102.

Ozawa T, Fujita E. Local deformations around volcanoes associated with the 2011 off the Pacific coast of Tohoku earthquake. J Geophys Res Solid Earth. 2013; 118(1):390-405

Ozawa T, Kozono T. Temporal variation of the Shinmoe-dake crater in the 2011 eruption revealed by spaceborne SAR observations. Earth, Planets and Space. 2013;65(6):5.

Pagli C, Wright TJ, Ebinger CJ, Yun SH, Cann JR, Barnie TL, Ayele A. Shallow axial magma chamber at the slow-spreading Erta Ale Ridge. Nat Geosci. 2012;5(4): 284-8.

Pallister, J.S., Schneider, D.J., Griswold, J.P., Keeler, R.H., Burton, W.C., Noyles, C., Newhall, C.G. and Ratdomopurbo, A. (2013). Merapi 2010 eruption, ÄîChronology and extrusion rates monitored with satellite radar and used in eruption forecasting. J Volcanol Geotherm Res, 261, 144-152.

Parker AL, Biggs J, Lu Z. Investigating long-term subsidence at medicine Lake volcano, CA, using multitemporal InSAR. Geophys J Int. 2014;199(2):844-59.

Parker AL, Biggs J, Walters RJ, Ebmeier SK, Wright TJ, Teanby NA, Lu Z. Systematic assessment of atmospheric uncertainties for InSAR data at volcanic arcs using large-scale atmospheric models: application to the Cascade volcanoes, United States. Remote Sens Environ. 2015;170:102-14.

Parker AL, Biggs J, Lu Z. Time-scale and mechanism of subsidence at Lassen volcanic center, CA, from InSAR. J Volcanol Geotherm Res. 2016;320:117-27.

Parks MM, Biggs J, Mather TA, Pyle DM, Amelung F, Monsalve ML, Medina LN Co-eruptive subsidence at Galeras identified during an InSAR survey of Colombian volcanoes (2006-2009). J Volcanol Geotherm Res. 2011;202(3):228-40.

Parks MM, Biggs J, England P, Mather TA, Nomikou P, Palamartchouk K, Papanikolaou X, Paradissis D, Parsons B, Pyle DM, Raptakis C. Evolution of Santorini volcano dominated by episodic and rapid fluxes of melt from depth. Nat Geosci. 2012;5(10):749.

Passarelli L, Brodsky EE. The correlation between run-up and repose times of volcanic eruptions. Geophys J Int. 2012;188(3):1025-45.

Peltier, A., Bianchi, M., Kaminski, E., Komorowski, J. C., Rucci, A., \& Staudacher, T. (2010). PSInSAR as a new tool to monitor pre-eruptive volcano ground deformation: Validation using GPS measurements on Piton de la Fournaise. Geophysical Research Letters, 37(12).

Phillipson G, Sobradelo R, Gottsmann J. Global volcanic unrest in the 21st century: An analysis of the first decade. J Volcanol Geotherm Res. 2013;264: 183-96.

Pinel V, Hooper A, De la Cruz-Reyna S, Reyes-Davila G, Doin MP, Bascou P. The challenging retrieval of the displacement field from InSAR data for andesitic stratovolcanoes: case study of Popocatepetl and Colima Volcano, Mexico. J Volcanol Geotherm Res. 2011;200(1):49-61.

Pinel V, Poland MP, Hooper A. Volcanology: lessons learned from synthetic aperture radar imagery. J Volcanol Geotherm Res. 2014;289:81-113.

Poland MP. Time-averaged discharge rate of subaerial lava at Kilauea volcano, Hawai'i, measured from TanDEM-X interferometry: implications for magma supply and storage during 2011-2013. J Geophys Res Solid Earth. 2014; 119(7):5464-81.

Poland M, Miklius A, Orr T, Sutton J, Thornber C, Wilson D. New episodes of volcanism at Kilauea volcano, Hawaii. EOS Trans Am Geophys Union. 2008; 89(5):37-8.
Poland MP, Lisowski M, Dzurisin D, Kramer R, McLay M, Pauk B. Volcano geodesy in the Cascade arc, USA. Bull Volcanol. 2017;79(8) https://doi.org/10.1007/ s00445-017-1140-x.

Pritchard, M.E. and Simons, M., 2004. An InSAR-based survey of volcanic deformation in the central Andes. Geochemistry, Geophysics, Geosystems, 5(2).

Pritchard ME, Jay JA, Aron F, Henderson ST, Lara LE. Subsidence at southern Andes volcanoes induced by the 2010 Maule, Chile earthquake. Nat Geosci. 2013;6(8):632-6.

Pritchard ME, Biggs J, Wauthier C, Sansosti E, Arnold DWD, Delgado F, Ebmeier SK, Henderson ST, Stephens K, Wnuk K, Amelung F, Mothes P, Macedo O, Lara L, Poland MP, Zoffoli S. Towards coordinated regional multi-satellite InSAR volcano observations: Results from the Latin America pilot project. n.d.: In prep.

Riddick SN, Schmidt DA. Time-dependent changes in volcanic inflation rate near Three Sisters, Oregon, revealed by InSAR. Geochem Geophys Geosyst. 2011; 12(12):Q12005.

Rivalta E, Segall P. Magma compressibility and the missing source for some dike intrusions. Geophys Res Lett. 2008;35(4)

Ruch J, Anderssohn J, Walter TR, Motagh M. Caldera-scale inflation of the Lazufre volcanic area, South America: evidence from InSAR. J Volcanol Geotherm Res. 2008; 174(4):337-44.

Segall, P. (2010). Earthquake and volcano deformation. Princeton University Press.

Sigmundsson, F. (2016), New insights into magma plumbing along rift systems from detailed observations of eruptive behavior at Axial volcano, Geophys. Res. Lett., 43, doi:https://doi.org/10.1002/ 2016GL071884.

Sigmundsson F, Hreinsdóttir S, Hooper A, Árnadóttir T, Pedersen R, Roberts MJ, Eskarsson N, Auriac A, Decriem J, Einarsson P, Geirsson H. Intrusion triggering of the 2010 Eyjafjallajokull explosive eruption. Nature. 2010;468(7322):426-30.

Sigmundsson F, Hooper A, Hreinsdóttir S, Vogfjörd KS, Ófeigsson BG, Heimisson ER, Dumont $S$, et al. Segmented lateral dyke growth in a rifting event at BarSarbunga volcanic system, Iceland. Nature. 2015a;517(7533):191-5.

Sigmundsson F, Hooper A, Hreinsdóttir S, Vogfjörd KS, Ófeigsson B, Rafn Heimisson E, Dumont S, Parks M, Spaans K, Gudmundsson GB, Drouin V. Contribution of the FUTUREVOLC project to the study of segmented lateral dyke growth in the 2014 rifting event at bardarbunga volcanic system, Iceland. In: EGU general assembly conference abstracts, vol. 17; 2015b. p. 11846.

Simons, M., \& Rosen, P. A. (2007). Interferometric synthetic aperture radar geodesy.

Solaro, G., Acocella, V., Pepe, S., Ruch, J., Neri, M., \& Sansosti, E. (2010). Anatomy of an unstable volcano from InSAR: Multiple processes affecting flank instability at Mt. Etna, 1994-2008. Journal of Geophysical Research: Solid Earth, 115(B10).

Sparks RSJ, Biggs J, Neuberg JW. Monitoring volcanoes. Science. 2012;335(6074): 1310-1.

Stephens, K. J., Ebmeier, S. K., Young, N. K., \& Biggs, J. (2017). Transient deformation associated with explosive eruption measured at Masaya volcano (Nicaragua) using Interferometric Synthetic Aperture Radar. Journal of Volcanology and Geothermal Research.

Takada Y, Fukushima Y. Volcanic subsidence triggered by the 2011 Tohoku earthquake in Japan. Nat Geosci. 2013;6(8):637-41.

Tilling Rl. The critical role of volcano monitoring in risk reduction. Adv Geosci. 2008;14:3-11.

Trasatti, E., F. Casu, C. Giunchi, S. Pepe, G. Solaro, S. Tagliaventi, P. Berardino et al. (2008)"The 2004-2006 uplift episode at Campi Flegrei caldera (Italy): Constraints from SBAS-DInSAR ENVISAT data and Bayesian source inference." Geophysical Research Letters 35, no. 7

Velez, M. L., Euillades, P., Blanco, M., \& Euillades, L. (2016). Ground deformation between 2002 and 2013 from InSAR observations. In Copahue Volcano (pp. 175-198). Springer Berlin Heidelberg.

Voight, B., Glicken, H., Janda, R. J., \& Douglass, P. M. (1981). Catastrophic rockslide avalanche of May 18. In The 1980 Eruptions of Mount St. Helens, Washington (Vol. 1250, pp. 347-377). US Geol. Surv. Prof. Pap.

Wadge G, Scheuchl B, Cabey L, Palmer MD, Riley C, Smith A, Stevens NF. Operational use of InSAR for volcano observatories: experience from Montserrat. In: Proc. FRINGE99 symposium (p. 8); 1999.

Wang, T., Poland, M. P. and Lu, Z. (2015). Dome growth at Mount Cleveland, Aleutian Arc, quantified by time series TerraSAR-X imagery. Geophysical Research Letters, Vol. 42, 24, pp 10,614,Äi10,621, doi: https://doi.org/10.1002/ 2015GL066784

Whelley PL, Jay J, Calder ES, Pritchard ME, Cassidy NJ, Alcaraz S, Pavez A. Postdepositional fracturing and subsidence of pumice flow deposits: Lascar Volcano, Chile. Bull Volcanol. 2012;74(2):511-31. 
Wicks, C. W., Dzurisin, D., Ingebritsen, S., Thatcher, W., Lu, Z., \& Iverson, J. (2002). Magmatic activity beneath the quiescent Three Sisters volcanic center, central Oregon Cascade Range, USA. Geophysical Research Letters, 29(7). Wicks CW, Thatcher W, Dzurisin D, Svarc J. Uplift, thermal unrest and magma intrusion at Yellowstone caldera. Nature. 2006;440(7080):72-5.

Wright TJ, Ebinger C, Biggs J, Ayele A, Yirgu G, Keir D, Stork A. Magmamaintained rift segmentation at continental rupture in the 2005 afar dyking episode. Nature. 2006;442(7100):291-4.

Wright TJ, Sigmundsson F, Pagli C, Belachew M, Hamling IJ, Brandsdóttir B, Keir D, Pedersen R, Ayele A, Ebinger C, Einarsson P, Lewi E, Calais E. Geophysical constraints on the dynamics of spreading centres from rifting episodes on land. Nat Geosci. 2012;5(4):242-50.

\section{Submit your manuscript to a SpringerOpen ${ }^{\bullet}$ journal and benefit from:}

- Convenient online submission

- Rigorous peer review

- Open access: articles freely available online

- High visibility within the field

- Retaining the copyright to your article

Submit your next manuscript at $\gg$ springeropen.com 